OPEN ACCESS

Edited by:

Lionel Apetoh,

Institut National de la Santé et de la

Recherche Médicale

(INSERM), France

Reviewed by:

Eric Tartour

Hôpital Européen Georges-Pompidou

(HEGP), France

Yang $\mathrm{Xu}$,

University of North Carolina at Chape

Hill, United States

*Correspondence:

Yulin Li

ylli@ilu.edu.cn

Yishu Wang

wangys@jlu.edu.cn

Zhi-Xiang Xu

zhixiangxu@jlu.edu.cn

Specialty section:

This article was submitted to

Cancer Immunity and Immunotherapy,

a section of the journal

Frontiers in Immunology

Received: 22 February 2019 Accepted: 28 May 2019

Published: 14 June 2019

Citation:

Shen X, Zhang L, Li J, Li Y, Wang Y and Xu Z-X (2019) Recent Findings in the Regulation of Programmed Death

Ligand 1 Expression.

Front. Immunol. 10:1337.

doi: 10.3389/fimmu.2019.01337

\section{Recent Findings in the Regulation of Programmed Death Ligand 1 Expression}

\author{
Xiangfeng Shen ${ }^{1}$, Lihong Zhang ${ }^{1}$, Jicheng $\mathrm{Li}^{2}$, Yulin $\mathrm{Li}^{1 *}$, Yishu Wang ${ }^{1 *}$ and Zhi-Xiang Xu ${ }^{1 *}$ \\ ${ }^{1}$ Key Laboratory of Pathobiology, Ministry of Education, Norman Bethune College of Medicine, Jilin University, Changchun, \\ China, ${ }^{2}$ Department of Physiology, College of Basic Medical Sciences, Jilin University, Changchun, China
}

With the recent approvals for the application of monoclonal antibodies that target the well-characterized immune checkpoints, immune therapy shows great potential against both solid and hematologic tumors. The use of these therapeutic monoclonal antibodies elicits inspiring clinical results with durable objective responses and improvements in overall survival. Agents targeting programmed cell death protein 1 (PD-1; also known as PDCD1) and its ligand (PD-L1) achieve a great success in immune checkpoints therapy. However, the majority of patients fail to respond to PD-1/PD-L1 axis inhibitors. Expression of PD-L1 on the membrane of tumor and immune cells has been shown to be associated with enhanced objective response rates to PD-1/PD-L1 inhibition. Thus, an improved understanding of how PD-L1 expression is regulated will enable us to better define its role as a predictive marker. In this review, we summarize recent findings in the regulation of PD-L1 expression.

Keywords: PD-L1 expression, intrinsic signals, extrinsic signals, anti-PD-1/PD-L1, immune checkpoint therapy

\section{INTRODUCTION}

With rapid development of immunotherapy for cancer treatment in decades, immune checkpoint therapy that mediates tumor cell death through the reactivated immune system has become the most attractive strategy for cancer therapy due to their impressive therapeutic efficacy. Immune checkpoints, a cluster of immune inhibitory receptors and their reciprocal ligands that negatively regulate the immune system function, are important for avoiding autoimmunity and for protecting collateral tissue from damage under physiological conditions. On the other hand, cancer cells could also make use of immune checkpoints to inhibit the activity of $\mathrm{T}$ cells, leading to the immune escape of tumors.

The role of immune checkpoints in the suppression of T cell activity has led to the development of immune checkpoint inhibitors in the treatment of cancer. Among the immune checkpoints, programmed cell death protein 1 (PD-1) and its ligand PD-L1 have stood out because of their proven value as therapeutic targets in a large number of malignancies. Inhibition of the PD1/PD-L1 axis contributes to important clinical advances in cancer therapy, including melanoma $(1,2)$, non-small cell lung cancer (NSCLC) (3-5), renal cell carcinoma (RCC) (6), Hodgkin's lymphoma $(7,8)$, bladder cancer $(9,10)$, head and neck squamous cell carcinoma (HNSCC) 
(11-13), Merkel-cell carcinoma (14), urothelial carcinoma (15), and microsatellite instable-high (MSI-H) or mismatch repairdeficient (dMMR) solid tumors (16-18). However, despite the considerable improvement in patient outcome that has been achieved with PD-1/PD-L1 blockade, the durable objective responses to the checkpoint therapeutics are various among different tumor types and limited in only a minority of patients. Intra-tumoral PD-L1 expression is generally associated with a better response to $\mathrm{PD}-1 / \mathrm{PD}-\mathrm{L} 1$ blockade in patients across multiple cancer types $(3,19-21)$. Therefore, in order to predict the efficiency and optimize the anti-PD-1/PD-L1 therapy alone or in combination, improving the understanding of the regulatory mechanisms of PD-L1 in cancer should be of utmost importance for not only identifying its role as biomarker but also for designing the synergistic treatment combinations. Here, we focus on the current knowledge of PD-L1 regulation.

\section{ANTI-PD-1/PD-L1 INHIBITORS AS IMMUNE CHECKPOINT THERAPY}

Although the immune system of our body should eliminate cancer cells as "foreign," the interactions between the immune system and cancer cells are complex. A natural balance called tolerance may be reached between immune response and cancer, where cancer cells are seen as "self." Furthermore, tumor cells may evade immune destruction by suppressing immunity through multiple mechanisms, thus called immune escape. $\mathrm{T}$ cell immunity, especially activation of cytotoxic $\mathrm{T}$ lymphocyte (CTL) determines the ultimate amplitude and quality of antitumor immune response. Signals from $\mathrm{T}$ cell receptor, which recognizes antigen along with the major histocompatibility complex (also known as human leukocyte antigen) presented on the surface of antigen-presenting cell (APC), and additional co-stimulatory signals provided by the engagement of $\mathrm{CD} 28$ on the $\mathrm{T}$ cell surface with $\mathrm{B} 7$ molecules (CD80 and CD86) on the APC, are required for $\mathrm{T}$ cell activation $(22,23)$. Activated T cells attack and eventually destroy tumor cells that express tumor-specific antigens as "foreign."

In addition to initiating proliferation and functional differentiation, $\mathrm{T}$ cell activation also induces the stimulation of inhibitory pathways (also known as checkpoint pathways), which eventually attenuate and terminate $\mathrm{T}$ cell responses (24-26). Many types of solid tumors generate an immunosuppressive microenvironment to avoid the destiny of being lysed by CTL through the inhibitory ligand called PD-L1 that is expressed on the surface of tumor cells $(27,28)$. PD-1 (CD279), which belongs to the CD28 family, is encoded by the PDCD1 gene located on chromosome $2 \mathrm{q} 37.3$ and is mainly expressed on activated $\mathrm{T}$ cells (29). It has two ligands, PD-L1 (CD274, B7-H1) and PD-L2 (CD273, B7-DC), with different expression patterns, which are, respectively, encoded by the CD274 and PDCD1LG2 genes located on chromosome 9p24.1. PD-L1 is expressed abundantly on immune cells (e.g., T cells, B cells, dendritic cells (DCs), and macrophages) and parenchymal tissue cells (mesenchymal stem cells, epithelial, endothelial cells, and brown adipocytes), as well as tumor cells. The expression of PD-L2 is considered to be mainly restricted to activated DCs and macrophages (30-33). Studies have shown that PD1/PD-L1 axis can be hijacked by tumors as a co-inhibitory pathway to compromise the immune response toward cancer via blocking proliferation, induction of apoptosis by CTL, and promotion of regulatory $\mathrm{T}$ cell differentiation, which eventually induces an immunosuppressive microenvironment in tumor $(25,26)$. Considering that PD-L1 overexpression is a situation that is commonly seen in tumors and usually confers a poor prognosis, the therapeutic intervention targeting this co-inhibitory axis is substantially enticing to researchers and patients (34-37). Antibodies blocking the interaction between PD-1 and PD-L1 by either targeting PD-1 (pembrolizumab, nivolumab, and cemiplimab) or PD-L1 (atezolizumab, avelumab, and durvalumab) (Table 1) both induce durable objective responses in patients with melanoma $(1,2)$, NSCLC (3-5) and RCC (6), and other malignancies (7-15). Although the immune checkpoint therapy targeting either PD-1 or PD-L1 has been usually recognized as the same subclass in the field of tumor immunotherapy at present, PD-1 and PD-L1 blockades may differ in the mechanism of action due to the complicated subtle interactions among the immune checkpoint system. For example, in addition to $\mathrm{PD}-1$, studies have reported that co-stimulatory molecule CD80 (B7-1) can also serve as a receptor for $\mathrm{PD}-\mathrm{L} 1$, and the binding affinity of CD80 to $\mathrm{PD}-\mathrm{L} 1$ is comparable to its affinity for CD28 (38). More importantly, the binding of PD-L1 to CD80 functionally inhibits the proliferation of $\mathrm{T}$ cells and promotes the apoptosis of activated CD8 ${ }^{+} \mathrm{T}$ cells $(38,39)$. Similarly, in addition to PD-L1, PD-1 also binds to its ligand PD-L2, which is expressed on solid tumor cells and hematological malignancies (40-45) and bears an impact on the anti-PD-1 therapy $(41,42,46)$. Furthermore, PD-L2 has even been characterized as a novel potential therapeutic target for cancer treatment (45). Therefore, more evidence is needed to underpin the unique characteristics of PD-1 and PD-L1 inhibitors in order to achieve a better understanding of their differences.

\section{PD-L1 REGULATION IN CANCER}

Expression of PD-L1 is complicated and various in different tumor types. It can be regulated by various intrinsic and extrinsic signals, such as chromosomal alterations, epigenetic modifications, aberrant oncogenic and tumor suppressor signals, inflammatory cytokines, and other factors at the genetic, transcriptional, post-transcriptional, translational, and posttranslational levels.

\section{Genetic Basis of PD-L1 Expression in Cancer}

The genetic aberrations of the chromosome 9p24.1, on which CD274 resides, represent a key mechanism affecting PD-L1 expression. Copy number alterations (CNAs) in chromosome $9 \mathrm{p}$ involving $P D-L 1$ were recently detected in 22 cancer types (47). It revealed that gains of copy numbers in chromosome 
TABLE 1 | Characteristics of current FDA-approved PD-1/PD-L1 checkpoint blockades.

\begin{tabular}{|c|c|c|c|c|c|}
\hline Drug & $\begin{array}{l}\text { Brand } \\
\text { name }\end{array}$ & Target & Company & $\begin{array}{l}\text { Time } \\
\text { approved }\end{array}$ & FDA approved indications \\
\hline Pembrolizumab & Keytruda & PD-1 & Merck & $\begin{array}{l}09 / 04 / 2014 \\
12 / 18 / 2015 \\
08 / 05 / 2016 \\
03 / 15 / 2017 \\
05 / 18 / 2017 \\
05 / 10 / 2017 \\
\\
05 / 23 / 2017 \\
09 / 22 / 2017 \\
06 / 12 / 2018 \\
06 / 13 / 2018\end{array}$ & $\begin{array}{l}\text { Metastatic NSCLC } \\
\text { Unresectable or metastatic melanoma } \\
\text { Recurrent of metastatic HNSCC } \\
\text { Refractory CHL } \\
\text { Advanced or metastatic urothelial carcinoma } \\
\text { Untreated metastatic non-squamous NSCLC (combined with } \\
\text { pemetrexed and carboplatin) } \\
\text { Unresectable or metastatic MSI-H or dMMR solid tumors } \\
\text { Advanced gastric cancer } \\
\text { Recurrent or metastatic cervical cancer } \\
\text { Refractory PMBCL }\end{array}$ \\
\hline Nivolumab & Opdivo & PD-1 & $\begin{array}{l}\text { Bristo-Myers } \\
\text { Squibb }\end{array}$ & $\begin{array}{l}12 / 22 / 2014 \\
03 / 04 / 2015 \\
10 / 09 / 2015 \\
11 / 23 / 2015 \\
05 / 17 / 2016 \\
11 / 10 / 2016 \\
02 / 02 / 2017 \\
08 / 01 / 2017 \\
09 / 22 / 2017 \\
12 / 20 / 2017 \\
07 / 10 / 2018\end{array}$ & $\begin{array}{l}\text { Unresectable or metastatic melanoma } \\
\text { Metastatic squamous NSCLC } \\
\text { Metastatic NSCLC } \\
\text { Untreated advanced renal cell carcinoma } \\
\text { Relapsed cHL } \\
\text { Recurrent or metastatic HNSCC } \\
\text { Advanced or metastatic urothelial carcinoma } \\
\text { MSI-H or dMMR metastatic CRC } \\
\text { HCC previously treated with sorafenib } \\
\text { Resectable or metastatic melanoma } \\
\text { Advanced RCC (Combined with ipilimumab) }\end{array}$ \\
\hline Cemiplimab & Libtayo & PD-1 & Sanofi/Regeneron & 09/28/2018 & Metastatic CSCC \\
\hline Atezolizumab & Tecentriq & PD-L1 & Genetech/Roche & $\begin{array}{l}05 / 18 / 2016 \\
10 / 18 / 2016\end{array}$ & $\begin{array}{l}\text { Advanced or metastatic urothelial carcinoma } \\
\text { Metastatic NSCLC }\end{array}$ \\
\hline Avelumab & Bavencio & PD-L1 & EMD Serono & $\begin{array}{l}03 / 23 / 2017 \\
05 / 09 / 2017\end{array}$ & $\begin{array}{l}\text { Metastatic MCC } \\
\text { Advanced or metastatic urothelial carcinoma }\end{array}$ \\
\hline Durvalumab & Imfinzi & PD-L1 & AstraZeneca & $\begin{array}{l}05 / 01 / 2017 \\
02 / 16 / 2018\end{array}$ & $\begin{array}{l}\text { Advanced or metastatic urothelial carcinoma (UK Limited) } \\
\text { Unresectable stage III NSCLC }\end{array}$ \\
\hline
\end{tabular}

FDA, US Food and Drug Administration; PD-1, programmed death protein 1; PD-L1, programmed death ligand-1; NSCLC, non-small cell lung cancer; HNSCC, head and neck squamous cell carcinomas; CHL, classical Hodgkin lymphoma; MSI-H, microsatellite instability-high; dMMR, mismatch repair-deficient; PMBCL, primary mediastinal large B-cell lymphoma; CRC, colorectal cancer; HCC, hepatocellular carcinoma; RCC, renal cell carcinoma; CSCC, cutaneous squamous cell carcinoma; MCC, Merkel cell carcinoma.

9p occur frequently in bladder, breast, cervical, colorectal, head and neck, and ovarian carcinomas, but are a rare event in pancreatic, renal cell, and papillary thyroid carcinoma. On the other hand, $P D-L 1$ gene deletions were found to be more frequent than $P D-L 1$ gains in cancers, especially in melanoma and NSCLC (>50\%). Generally, overexpression of PD-L1 frequently occurs in tumors coupled with copy number gains, especially amplification of the $P D-L 1$ gene. Other studies also revealed high CNAs in classical Hodgkin lymphoma (cHL) and primary mediastinal B-cell lymphoma $(48,49)$. A recent study showed that the CNAs of $P D-L 1$ are also prevalent in soft-tissue sarcomas $(21.1 \%)$, with higher frequency in myxofibrosarcoma (35\%) and undifferentiated pleomorphic sarcoma (34\%) (50). In contrast, absence or low frequency of CNAs has been reported in lung cancer (51-53) and diffuse large B-cell lymphoma (DLBCL) (54).

In addition to the CNAs, a previous study confirmed that a somatic mutation at a naturally occurring polymorphism locus, rs4143815, in the $3^{\prime}$ untranslated region (3'-UTR) of $P D-L 1$ gene is correlated with elevated PD-L1 protein expression in gastric cancer $(55,56)$. Another polymorphism in the promoter region of $P D-L 1$ was verified to upregulate $P D-L 1$ mRNA and protein expression by offering a binding site for transcriptional factor SP1 in gastric cancer (57). The disruption of $P D$-L1 3'-UTR was further confirmed to invariably lead to a marked elevation of aberrant $P D-L 1$ transcripts. Using whole-genome sequencing, Kataoka et al. (58) identified a novel genetic mechanism termed structural variants for PD-L1 overexpression in adult $\mathrm{T}$ cell leukemia/lymphoma (ATL), DLBCL, and gastric adenocarcinoma. These structural variants invariably generate $P D-L 1$ transcripts with aberrant $3^{\prime}$-UTR, leading to a delayed clearance of the transcripts and elevated PD-L1 expression. Furthermore, expression of $3^{\prime}$-UTR-truncated $P D-L 1$ transcripts in EG7-OVA cells contributes to tumor immune evasion in a mouse model, which is effectively inhibited by PD-1/PD-L1 blockade. Kogure and Kataoka (59) also reported that structural variants induce PD-L1 overexpression in ATL. More recently, a study in gastric cancer has revealed that $P D-L 1$ rs 2297136 $\mathrm{AA}+\mathrm{AG}$ genotype, a new polymorphism in $3^{\prime}$-UTR of $P D$ $L 1$, is also correlated with the positive protein expression of PD-L1 (60). 


\section{Epigenetic Regulation of PD-L1 Expression in Cancer}

DNA methylation and post-translational histone modifications, the most foundational epigenetic events, are central mechanisms in cancer development and progression $(61,62)$. Both of them contribute to immunosuppressive environment within tumors by manipulating the expression of genes associated with the process of antigen presentation, immune evasion, and T-cell exhaustion $(63,64)$. Hypomethylating agents and histone deacetylase inhibitors enhance the processing and presentation of tumor-associated antigens and promote the expression of additional immune-related genes, chemokines, and co-stimulatory molecules $(65,66)$, hence reversing the immune suppression. It suggests that the efficacy of epigenetic agents is dependent, at least in part, on adaptive immune responses. Interestingly, recent studies on the role of epigenetics in immune evasion have identified a role for epigenetic modulators in the upregulation of immune checkpoint. Yang et al. (67) reported that application of hypomethylating agents elevates $\mathrm{PD}-\mathrm{L} 1$, which is responsible for the resistance of patients to the original treatment. As a corollary, a blockade of the PD-1/PD-L1 axis may be an option to help overcome the resistance. On the other hand, sufficient expression of PD-L1 within tumor microenvironment is the basis for anti-PD-1/PDL1 therapy. Deficiency of PD-L1 could contribute to "target missing" resistance (68). Treatments leading to the upregulation of PD-L1 within a tumor may sensitize PD-1/PD-L1 checkpoint therapy. Therefore, it is possible that combined application of epigenetic therapies with PD-1/PD-L1 inhibitors will exhibit a synergy antitumor effect through the altered expression of PDL1, as well as the host immune response.

\section{DNA Methylation}

Recent studies suggested that the DNA methylation status of the $P D-L 1$ promoter can serve as a prognostic biomarker in various malignancies (69-72). There are robust data to support that DNA methylation plays a fundamental role within the dynamic expression of the PD-L1. In melanoma, both the changes in global methylation and the DNA methylation of CpG loci in the $P D-L 1$ promoter are involved in regulating the expression of PD-L1 $(72,73)$. Consistently, hypomethylation of the $P D$ L1 promoter was found to be inversely correlated with both mRNA and protein expression in HNSCC (74). In glioma, the cancer genome atlas (TCGA) data showed that cytosolic $\mathrm{NADP}^{+}$-dependent isocitrate dehydrogenase 1 (IDH1) mutation tumors represent an attenuated level of PD-L1 expression accompanied by higher $P D-L 1$ gene promoter methylation $(75,76)$. Supportively, the addition of 2-hydroxyglutarate, key production of IDH1 mutation, transiently showed efficacy to elevate the DNA methylation in CpG site within $P D-L 1$ and diminish the expression of PD-L1 (76). Moreover, it was reported that transforming growth factor $\beta 1$ (TGF $\beta 1$ ) induces decreased expression of DNA methyltransferase 1 (DNMT1) and PD-L1 promoter demethylation, which subsequently results in PDL1 overexpression in lung cancer cells undergoing epithelialmesenchymal transition (EMT) (77). These results spark significant interest in detecting the effect of hypomethylating agents on PD-L1 expression and the combination efficiency of this epigenetic therapy and anti-PD-1/PD-L1 inhibitors. As expected, decitabine, which induces the inhibition of global methylation, upregulates the transcript and protein of PDL1 in NSCLC cell lines (78). In a study in myelodysplastic syndrome, a high level of PD-L1, PD-L2, PD-1 and cytotoxic T lymphocyte associated antigen 4 (CTLA4) expression was observed in patients treated with decitabine (67). Furthermore, the supplement of decitabine to anti-PD-1 therapy improves the efficiency of antitumor immunity $(79,80)$. Of note, anti-PD-1 therapy enhanced $P D-L 1$ promoter methylation was identified to be involved in the resistance to immune checkpoint inhibitor in NSCLC (80).

\section{Histone Modifications}

Histone deacetylases (HDACs) have pleiotropic efficiency in regulating immune response (81). HDAC inhibitors have been evaluated as anticancer drugs over the past two decades (82). The role of HDACs in immunotherapies has recently been investigated $(65,83-86)$. In melanoma, inhibition of HDAC8, a class I histone deacetylase, was proven to elevate the expression of PD-L1 via increasing the activity of a fragment of the $P D$ L1 promoter (87). Another study also demonstrated the durable upregulation effect of three class I histone deacetylase inhibitors on PD-L1 due to enhanced histone acetylation of the $P D-L 1$ gene in melanoma (88). In contrast, Lienlaf et al. (89) have described a negative effect of HDAC6 (a class IIb histone deacetylase) inhibition or depletion on PD-L1 expression, which is mediated by activated signal transducer and activator of transcription 3 (STAT3). Both HDAC6 and STAT3 are recruited to the PDL1 gene promoter in melanoma. Consistently, in a study in multiple myeloma, ACY241 (an HDAC6 selective inhibitor) significantly decreases PD-L1 expression on $\mathrm{CD} 138^{+}$myeloma cells in patients (90). In a recent study by Booth et al. (86), two pan-HDAC inhibitors were found to decrease the expression of PD-L1 both in vitro and in vivo. The authors argued that knockdown of HDAC1 and HDAC2, members of the class I histone deacetylase family, contributes to the reduced expression of PD-L1, but not HDAC6 and HDAC10, which belong to the class IIb histone deacetylase family (86). Discrepancy of HDACs inhibitors in regulating PD-L1 expression was also reported in lung cancer $(65,83,91)$.

In addition to HDACs, in a screening for epigenetic mechanisms that regulate PD-L1 expression in pancreatic cancer, histone methylation (H3K4me3) is evident to be enriched in the proximal CD274 promoter region both in vitro and in vivo. Chromatin immunoprecipitation (ChIP) analysis revealed that MLL1, one of the H3K4 methylationspecific histone methyltransferases, is directly associated with the CD274 promoter region. Silencing MLL1 expression dramatically decreases the H3K4me3 level in the CD274 promoter region, leading to a decreased $P D-L 1 \mathrm{mRNA}$ in both human and mouse pancreatic cancer cells (92).

Whilst the regulation of DNA methylation and histone modifications in PD-L1 expression has been explored, a novel epigenetic drug, JQ1, a selective bromodomain inhibitor (BETi), was corroborated to suppress PD-L1 expression in ovarian cancer 
to restore cytotoxic T cell responses (93). Another study reported by Hogg et al. (94), corroborated that both constitutive and inducible expression of PD-L1 can be directly repressed at transcriptional level in different tumor cell lines and primary patient samples via decreasing the occupancy of bromodomain and extraterminal protein at the CD274 locus. Downregulation of PD-L1 plays a crucial role in JQ1 mediated anti-cancer therapy since ectopic expression of PD-L1 blunted the therapeutic effect of JQ1. The role of BET inhibition in modulating PDL1 expression was further confirmed by Cioffi et al. revealing that OTX015 (a BETi) diminishes the expression of CD274 via upregulating miR-93 and miR-106b (95). Furthermore, JQ1 in combination with anti-PD-1 antibody enhances antitumor responses in mice bearing Myc-driven lymphomas and KRASdriven NSCLC (94).

\section{Non-coding RNAs}

MicroRNAs (miRs) are a group of small non-coding RNAs known to regulate target genes at the post-transcriptional level (96). Adding to the growing body of evidence, the role of miRs in regulating PD-L1 expression via several mechanisms has been demonstrated. In general, most miRs are negatively correlated with PD-L1 through inducing the degradation or translational repression of $P D-L 1$ mRNA by direct binding to $P D-L 13^{\prime}$ UTR, whereas several miRs are found to be positively connected with PD-L1 expression. For example, MiR-3127-5p and miR135 are associated with elevated levels of PD-L1 in NSCLC by targeting STAT3 and TRIM16/JAK/STAT, respectively $(97,98)$. MiR-20b, miR-21, miR-130b, and miR-142-5P induce PD-L1 overexpression via inhibiting phosphatase and tensin homolog (PTEN) $(99,100)$. The detailed information for miR-mediated PD-L1 regulation is delineated in Table 2 (95, 97-128).

Moreover, the profiled miRs in serum from NSCLC patients uncover seven miRs (miR-215-5p, miR-411-3p, miR- 493-5p, miR-494-3p, miR-495-3p, miR-548j-5p, miR-93-3p) strongly associated with overall survival after treatment with the immune checkpoint inhibitor, nivolumab (129). In addition, a study in CRC highlights the role of circular RNA in accommodating PDL1 expression, revealing that circular RNA has_circ_0020397 promotes the expression of PD-L1 by inhibiting miR-138 activity (130). More importantly, a very recent study has identified miR-146a as a comparable immune checkpoint molecule in melanoma, and a miR-146a antagomiR combined with anti-PD-1 enhances the anti-tumor effect of anti-PD-1 therapy, suggesting that miRNAs may be a novel combination target for immune checkpoint therapy (131).

\section{Extrinsic Control of PD-L1 Expression Virus Infection and Inflammatory Signaling}

Although a generalized conclusion for PD-L1 expression in virus infection remains uncertain as comparable levels of PD-L1 were detected in individuals with or without infection $(74,132-$ 134), escalated PD-L1 levels were shown to be connected with specific viruses, such as Epstein-Barr virus (EBV) (135-139), hepatitis B viral (HBV) $(114,140,141)$, hepatitis C virus (HCV) (142-146), human immunodeficiency virus (HIV) (132, 147150), human papilloma virus (HPV) (135, 151-155), Merkel cell polyomavirus (MCPyV) (156), bovine leukemia virus (BLV) (157), and Kaposi sarcoma-associated herpes virus (KSHV) (158). The pathobiological mechanisms by which viruses trigger the expression of PD-L1 were revealed. Pathogen associated molecular patterns (PAMPs) stemming from a pathogen (for example virus, bacteria, and fungi) activate toll like receptors (TLRs) to initiate the immune response and protect the host against pathogens infection. TLR agonists-induced synthesis of PD-L1 has been observed in a variety of cell types (159-164). PAMPs from EBV was reported to induce PD-L1 upregulation in a TLR-dependent manner $(136,165,166)$. Similarly, HIV stimulates PD-L1 expression on APC via TLR signaling or in an indirect manner by increasing the production of cytokines $(149,150)$. Several downstream signaling pathways activated by virus infection, such as JAK/STAT, MAPK, and NF-кB signaling, are involved in both TLR agonists- and virus infection-mediated regulation of PD-L1 (114, 137, 138, 159, 161, 166), further supporting the notion that TLR signaling serves as an effector for the induction of PD-L1 upon virus infection. TLRs-independent induction of PD-L1 in virus infection was also uncovered (114, $139,148)$. For an example, amplification of $P D-L 1$ gene, a major cause of PD-L1 overexpression, was observed in EBV-positive gastric tumors (139).

Persistent infections of pathogens lead to chronic inflammation via promoting the secretion of inflammatory cytokines. Pro-inflammatory molecules or cytokines, such as IFN- $\gamma$, IFN- $\alpha$, IFN- $\beta$, TNF- $\alpha$, EGF, IL-17, IL-4, and IL-27 have been reported to induce PD-L1 expression in tumors (167-175). Among them, IFN- $\gamma$ is the most potent inducer of PD-L1. Upregulation of PD-L1 by IFN- $\gamma$ has been extensively described in diverse cell types $(31,168,176-179)$. PD-L1, largely induced locally at the tumor by tumor-infiltrating lymphocytes (TILs)derived IFN- $\gamma$, which are termed adaptive immune resistant, was first reported in melanomas by Taube et al. (180) and Abiko et al. (181). JAK/STAT and NF-кB pathways are the main downstream signals in the inflammation for IFN- $\gamma$-induced PD-L1 expression $(170,182-184)$. Another transcriptional mechanism is used for controlling the expression of PD-L1 by IFN- $\gamma$ in melanoma and medulloblastoma, in which activation of JAK/STAT signal increases the expression of a series of transcription factors named the interferon-responsive factors (IRFs) (182, 185). Likewise, TNF- $\alpha$, another pro-inflammatory cytokine, upregulates PD-L1 expression via TNF- $\alpha-N F-\kappa B$ pathway $(167,170,172,186)$. Furthermore, TNF- $\alpha$ was reported to synergistically act with IFN- $\gamma$ to induce PD-L1 expression at both mRNA and protein levels and enhance the adaptive immune resistance mediated by IFN- $\gamma$-induced PD-L1 in hepatocellular carcinoma cells via upregulating the expression of IFN- $\gamma$ receptors (187).

\section{Transforming Growth Factor $\beta$ (TGF- $\beta$ )}

TGF- $\beta$, which is generally considered as an anti-inflammatory cytokine, plays a paradox role in cancer. High levels of TGF- $\beta$ render tumor cells capable of escaping immune surveillance (188-190). It was recently reported that TGF- $\beta$ elevated PD-L1 expression. In lung cancer, TGF- $\beta$-mediated EMT facilitates PD-L1 expression through an epigenetic mechanism $(77,191,192)$. Consistently, TGF- $\beta$-induced EMT 
TABLE 2 | microRNAs regulate PD-L1 expression.

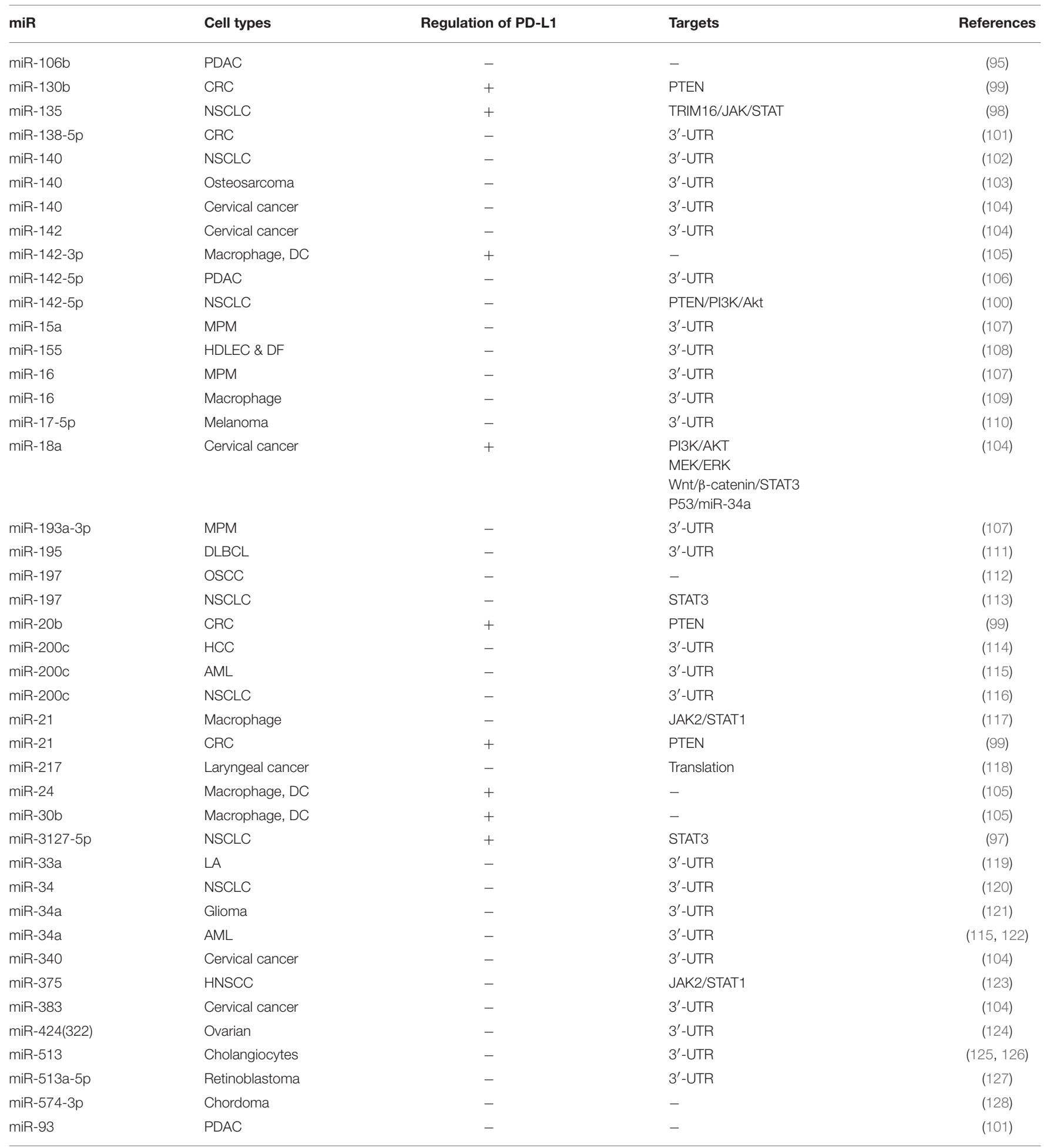

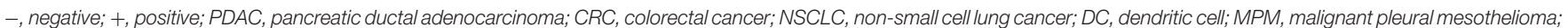

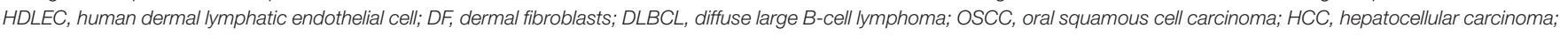

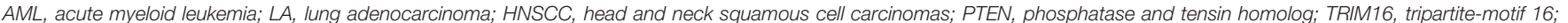

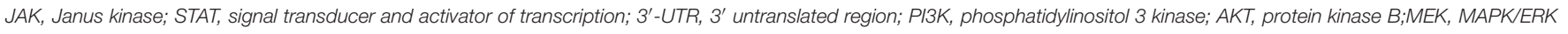
kinase; ERK, extracellular regulated protein kinases; P53, protein 53. 
was recently revealed to promote PD-L1 expression by posttranslational modification. EMT transcriptionally upregulates $\mathrm{N}$ glycosyltransferase STT3 through $\beta$-catenin, and STT3 further glycosylates and stabilizes PD-L1 (193). In the mouse model of pancreatic islet transplantation, TGF- $\beta$ was found to be necessary for the sustained expression of PD-L1 on $\mathrm{CD}^{+} \mathrm{T}$ cells via autocrine (194). These findings highlight that the role of TGF$\beta$ in the regulation of PD-L1 may possibly account for the link between TGF- $\beta$ and immune evasion.

In addition, TGF- $\beta$ shapes the tumor microenvironment to restrain antitumor immunity by restricting $\mathrm{T}$ cell infiltration and attenuating the efficacy of PD-L1 blockade antibody. TGF$\beta$ inhibitor and PD-L1 blockade together provoke vigorous antitumor immune response and tumor regression $(189,190)$. M7824, a novel bifunctional anti-PD-L1/TGF- $\beta$ with a soluble extracellular domain of TGF- $\beta$ receptor II, elicits potent and superior antitumor activity in preclinical and clinical studies (195-197).

\section{Hypoxia}

Hypoxia, an inevitable outcome due to the abnormal vasculature and a huge mass of tumor, is represented as a hallmark of a tumor microenvironment. Under the hypoxic environment, tumor cells survive themselves by reprogramming the gene expression through activating a series of hypoxia-inducible factors (HIFs). Among these HIFs, HIF-1 $\alpha$, and HIF- $2 \alpha$ are the most important transcript factors responsive to hypoxia, leading to the adaption to the stress $(198,199)$. Hypoxia signaling represents an important pathway in immune evasion (200-202). Hypoxia markedly induces the expression of PD-L1 on the surface of myeloid-derived suppressor cells (MDSCs), macrophages, DCs, monocytes, and tumor cells $(201,203,204)$. Exposure of human or murine cancer cells to hypoxia leads to the upregulation of PD-L1, which induces $\mathrm{T}$ cell apoptosis in a HIF-1 $\alpha$-dependent manner. Furthermore, blocking the accumulation of HIF- $1 \alpha$ in hypoxic cells by glyceryl trinitrate prevents hypoxia-induced PDL1 expression (201). In another study, inhibiting HIF-1 $\alpha$ through gene knockdown or PX-478 treatment also strikingly attenuates the elevation of PD-L1 induced by $\mathrm{CoCl}_{2}$ (a hypoxia-mimic treatment) (205). Likewise, PD-L1 overexpression on monocytes is induced both in vitro and in vivo models of intermittent hypoxia, and by HIF-1 $\alpha$ gene transfection (204). Moreover, HIF- $1 \alpha$ was demonstrated to translocate into the nucleus and drive PD-L1 expression in human monocytes during endotoxin tolerance (206). Direct binding of HIF- $1 \alpha$ to the promoter of $P D-L 1$ via hypoxia response element (HRE) has been unveiled in MDSCs by ChIP and luciferase reporter assay (203). Collectively, PD-L1 expression is regulated by HIF- $1 \alpha$ in monocytes and tumor cells, including melanoma cells, breast cancer, prostate cancer, and lung cancer cells (201, 203, 204, 207). However, in clear cell renal cell carcinoma (ccRCC), cells with VHL (a component of oxygen and iron sensing pathway that regulates the HIF) mutation, HIF- $2 \alpha$, rather than HIF- $1 \alpha$, is specifically able to induce PD-L1 expression (208). The association between HIF-2 $\alpha$ and PD-L1 was further verified in ccRCC by Messai et al. (209), where a direct binding of HIF- $2 \alpha$ to a transcriptionally active HRE in human PD-L1 proximal promoter was revealed.
Angiogenesis in solid tumors is a multiple biological process that is induced by the overexpression of pro-angiogenic factors in the environment to support the tumor cell growth. However, in contrast to the vasculature of normal tissues, tumor vessels are usually twisted and disorganized accompanied with a reduced blood perfusion and oxygenation. Normalization of tumor vasculature with an appropriate dose of anti-angiogenic treatment, primarily through disruption of the VEGF/VEGFR axis, is able to reduce tissue hypoxia and reprogram the tumor microenvironment from immunosuppressive to immunoactive (210, 211). Remarkably, PD-L1 expression is positively correlated with VEGF and microvessel density in patients with uniformly treated cHL (212). Considering that hypoxia is capable of inducing PD-L1 expression, addition of anti-angiogenic reagent to PD-1/PD-L1 antibodies is likely to sensitize immune checkpoint therapy. This conjecture has been verified in both animals and human beings. For example, a preclinical study showed that combined anti-VEGF/anti-PD-L1 targeted therapy synergistically improves the treatment outcome, compared to both anti-PD-L1 or anti-VEGF monotherapy in an autochthonous mouse model of small cell lung cancer (SCLC) (213). Similarly, preliminary results from a phase III study (NCT02366143), which evaluated the efficacy of bevacizumab (the first anti-angiogenic drug) plus atezolizumab plus chemotherapy, bevacizumab plus chemotherapy, and atezolizumab plus chemotherapy in non-squamous NSCLC, has also revealed superior outcomes in patients receiving the first treatment (214). Choueiri et al. (215) recently reported a phase Ib trial based on avelumab plus axitinib, a VEGF receptor inhibitor as first-line therapy in patients with advanced ccRCC (NCT02493751). McDermott et al. (216) performed a phase II study of atezolizumab alone or combined with bevacizumab vs. sunitinib in treatment-naive metastatic RCC, and the preliminary data on antitumor activity are encouraging. A phase III trial assessing avelumab and axitinib compared with sunitinib monotherapy for first-line treatment of advanced RCC is ongoing (NCT02684006).

\section{Previous Treatments}

Radiation and conventional antineoplastics that are currently used for cancer therapy, such as chemotherapeutic drugs and epigenetic modifiers, may promote immunogenic cell death via introducing DNA damage. Importantly, it is increasingly evident that conventional radiotherapies and chemotherapies, as well as novel epigenetic modifiers and targeted anticancer agents cannot only induce tumor regression by triggering immunogenic death of tumor cells, but also result in tumor progression by dysregulating the immune system, including changes within inhibitory molecules across a wide range of malignancies. Radiation and a number of chemotherapy drugs induce PDL1 expression through different mechanisms, which are likely responsible for the loss of antitumor immunity and acquired resistance $(217,218)$. Remarkably, the PD-1/PD-L1 pathway blockade reverses adaptive immune resistance and maintains the antitumor immunity (219-221). Of note, although radiation and most chemotherapies enhance PD-L1 expression upon most occasions, inconsistent results were also obtained. The detailed 
information and involved signal pathways are listed in Table 3 $(67,78,113,122,127,193,217,220-255)$.

In addition to the genotoxicity therapy aforementioned, the correlations between PD-L1 expression and target therapy, as well as immunotherapy, were also documented. For example, epidermal growth factor receptor (EGFR), a commonly mutated oncogene in NSCLC, was reported to be associated with PDL1 upregulation (256). Treatment with EGFR tyrosine kinase inhibitors (EGFR-TKIs) results in the downregulation of PDL1 $(240,256,257)$. In parallel, application of BRAF and MEK inhibitors is also associated with decreased PD-L1 expression (258). Interestingly, PD-L1 expression is upregulated through both JUN and STAT3 after acquiring resistance to BRAF inhibition in the cells $(258,259)$, and hence, the expression level of PD-L1 may serve as a biomarker for predicting the probability of response to the inhibitors (260). Different from EGFR and BRAF inhibitors, sorafenib, a multi-target antitumor drug, increases PD-L1 expression through inducing tumor hypoxia (261). Furthermore, several immunotherapies were found to upregulate PD-L1 expression $(262,263)$. Rice et al. (262) revealed an increase in PD-L1 expression on tumor cells during an HPVE6/E7 immunotherapy. While the increased expression of PDL1 is blunted and even reversed when combined with antiPD-1 antibody, as a reduction in tumor PD-L1 expression was observed. These observations imply a role of anti-PD-1 therapy for regulating PD-L1. What's more, the dynamic change of PDL1 expression on circulating tumor cells in advanced solid tumor patients undergoing PD-1 blockade therapy might serve as a predictor to indicate the therapeutic response at an early time (264). Collectively, these studies may open up new avenues for developing rational combination of cancer therapeutics in various solid tumors.

\section{Intrinsic Control of PD-L1 Expression}

Abnormal signal transductions induced by intrinsic oncogenic activation or loss of tumor suppressor can both regulate PD-L1 expression at various levels.

\section{Oncogenic Signaling}

Apart from the reports described above, the intrinsic cellular changes associated with PD-L1 expression have attracted much attention because such explorations can not only expand the investigation in regulatory mechanism of PD-L1, but also direct the concomitant use of immune checkpoint therapies and target therapies for optimizing clinical outcomes. Oncogenic signaling stemming from aberrant transcription factors, effectors and upstream receptors can regulate the expression of PD-L1.

A number of oncogenic transcription factors, such as MYC, AP-1, STAT, IRF1, HIF, and NF- $\mathrm{B}$, were reported to individually or cooperatively promote PD-L1 expression at the transcriptional level. MYC, a transcription factor governing a large number of gene expressions, plays a vital role in tumorigenesis through its multiple effects on tumor cells, typically by controlling cell proliferation and survival, and elevated expression of MYC was found in approximately $70 \%$ of human cancers (265). A recent study by Casey et al. (266) revealed a novel role of
MYC in cancer immunosurveillance. MYC binds to the $P D$ L1 promoter transcriptionally regulating PD-L1 expression. Similarly, transient transfection with MYC plasmids upregulates PD-L1 in anaplastic large-cell lymphoma (ALCL) cells with low endogenous PD-L1 (267). In line with these observations, both pharmacological inhibition and geneticsilencing of MYC reduce PD-L1 expression in tumor cells (266-268). Moreover, a very recent study revealed a translational mechanism of MYC-mediated PD-L1 upregulation by bypassing the repressive effect of non-canonical upstream open reading frames in the $5^{\prime}$ untranslated region of PD-L1 on its translation (269). Of note, the translational inhibitor, eFT508, possesses a potent inhibitive effect on the cancer progression and metastasis by targeting PD-L1 mRNA translation, disclosing a new strategy for immunotherapy in PD-1/PD-L1 axis blocking.

AP-1 is a dimeric transcription factor comprised of Jun, Fos, and ATF protein families (270). As the best-known member of the AP-1 family, c-Jun is implicated in PD-L1 expression. An increased expression of PD-L1 was found in BRAF inhibitorresistant melanoma cells. Knockdown of c-Jun results in a reduction of PD-L1 expression (259). AP-1 binding sites were identified in the first intron of $P D-L 1$, and c-Jun and JUNB have been shown to be recruited to the $P D-L 1$ promoter $(138,271)$. Co-activation of STAT3 with c-Jun further enhances the transcriptional activity of PD-L1 $(272,273)$. Accordantly, concurrent knockdown of STAT3 and c-Jun contributes to a synergistic downregulation of PD-L1 (259). Not surprisingly, activated STAT3 alone can also increase PD-L1 expression by directly acting on the promoter of PD-L1 in HNSCC and lymphoma cells $(267,274,275)$, and STAT3 silencing leads to the downregulation of PD-L1 in ALK-negative ALCL cells and KRAS-mutant NSCLC cells $(267,271)$. As previously described, STAT1 and IRF1/7, downstream effectors of STAT1, can also induce PD-L1 expression $(79,169,276)$. Similarly, HIF- $1 \alpha$ and HIF- $2 \alpha$ transcriptionally facilitate PD-L1 expression by binding to the HRE of its promoter $(203,209)$. Moreover, the interaction between STAT3 and HIF-1 involves in the regulation of HIF target genes. Inhibition of STAT3 decreases the expression of HIF-1 target genes in MDA-MB-231 and RCC4 cells (277), indicating a potentially cooperative effect for STAT3 and HIF-1 in regulating PD-L1. Binding of the RELA/p65-MUC1-C complex on the promoter of $P D-L 1$ was observed in NSCLC (278), suggesting that NF- $\mathrm{KB}$ may directly regulate $\mathrm{PD}-\mathrm{L} 1$ transcription. Besides the above transcription factors, recent work have verified nuclear factor E2-related transcription factor 2 (NRF2) as an upstream transcriptional activator of PD-L1 in human primary keratinocytes and melanocytes after ultraviolet-B irradiation, and depletion of NRF2 significantly increases T cells infiltration in the tumors and suppresses melanoma progression (234).

Oncogenic signaling initiated by activating mutations or amplification in receptor tyrosine kinases plays an important role in regulating PD-L1. The MEK-ERK pathway is commonly activated by mutations in RAS GTPase, BRAF, and EGFR (279), and there are now abundant data suggesting that MEK-ERK signaling upregulates PD-L1 expression. Coelho et al. (280) revealed that RAS stabilizes $P D-L 1$ mRNA and upregulates cell-intrinsic PD-L1 expression via phosphorylation 
TABLE 3 | Alteration of PD-L1 expression by previous treatments.

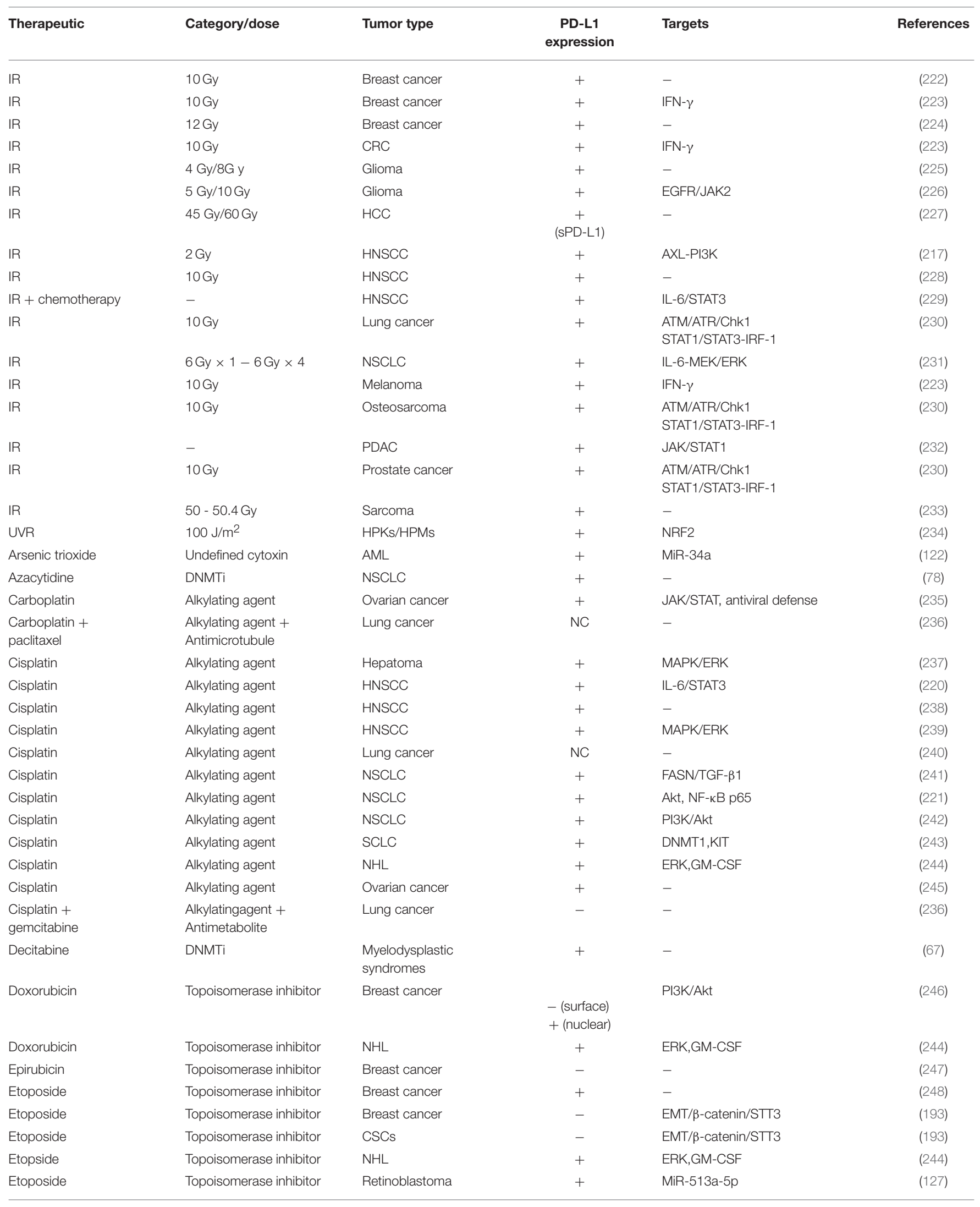


TABLE 3 | Continued

\begin{tabular}{|c|c|c|c|c|c|}
\hline Therapeutic & Category/dose & Tumor type & $\begin{array}{l}\text { PD-L1 } \\
\text { expression }\end{array}$ & Targets & References \\
\hline Gemcitabine & Antimetabolite & Pancreatic cancer & + & JAK/STAT1 & $(232,249)$ \\
\hline Oxaliplatin & Alkylating agent & CRC & + & $\mathrm{IFN}-\gamma$ & $(250)$ \\
\hline Oxaliplatin & Alkylating agent & $\mathrm{NHL}$ & + & ERK,GM-CSF & $(244)$ \\
\hline Oxaliplatin & Alkylating agent & Prostate cancer & + & TGF- $\beta$ & $(251)$ \\
\hline Paclitaxel & Antimicrotubule & Breast cancer & + & - & $(247,248)$ \\
\hline Paclitaxel & Antimicrotubule & $\mathrm{CRC}$ & + & ERK1/2 & $(251)$ \\
\hline Paclitaxel & Antimicrotubule & $\mathrm{HCC}$ & + & ERK1/2 & $(251)$ \\
\hline Paclitaxel & Antimicrotubule & Ovarian cancer & + & $N F-\kappa B$ & $(252)$ \\
\hline Paclitaxel & Antimicrotubule & Pancreatic cancer & + & JAK2/STAT1 & $(249)$ \\
\hline Platinum & Alkylating agent & NSCLC & + & MiR-197/CKSIB/STAT3 & $(113)$ \\
\hline Trabectedin & Undefined cytoxin & Ovarian cancer & + & IFN- $\gamma$ & (253) \\
\hline Vincristine & Alkaloid & $\mathrm{NHL}$ & + & ERK,GM-CSF & $(244)$ \\
\hline $\begin{array}{l}\text { Vinorelbine tubulin } \\
\text { inhibitor }\end{array}$ & Antimicrotubule & Lung cancer & - & EMT & $(240)$ \\
\hline 5-Fluorouracil & Antimetabolite & Breast cancer & + & - & $(248)$ \\
\hline 5-Fluorouracil & Antimetabolite & $\mathrm{CRC}$ & + & - & $(254)$ \\
\hline 5-Fluorouracil & Antimetabolite & $\begin{array}{l}\text { Esophageal } \\
\text { adenocarcinoma }\end{array}$ & + & - & (254) \\
\hline 5-fluorouracil & Antimetabolite & Pancreatic cancer & + & JAK2/STAT1 & (249) \\
\hline
\end{tabular}

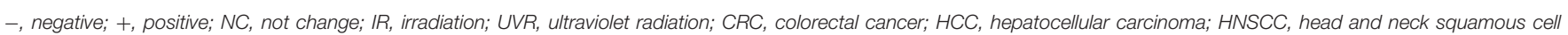

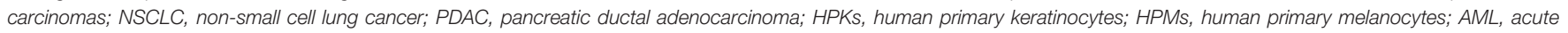

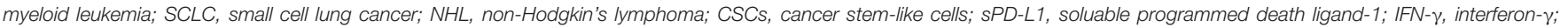

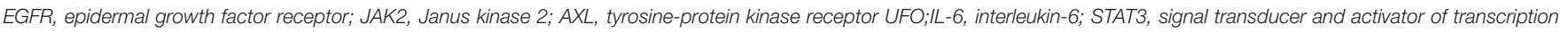

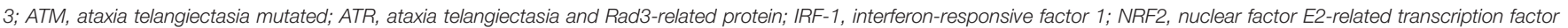

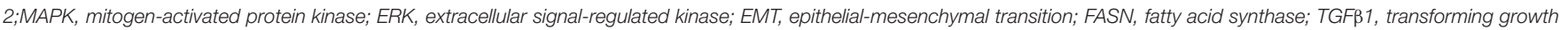

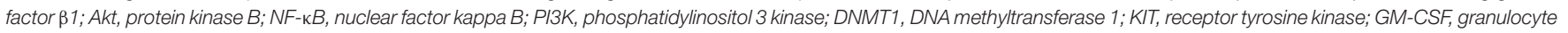
macrophage colony-stimulating factor; CKS1B, CDC28 protein kinase regulatory subunit $1 B$.

and inhibition of the adenylate-uridylate-rich element-binding protein, tristetraprolin, in a p38 MAPK-dependent manner. Furthermore, MAPK signaling is responsible for the increased expression of PD-L1, since inhibition of MEK or ERK partially offset the ectopic expression of PD-L1 in both mouse and human KRAS-mutant lung cancer cells $(271,280,281)$. However, in contrast to the positive relationship between MEK-ERK signaling and PD-L1 expression observed in most studies, MEK inhibitors are unable to change the PD-L1 expression in melanoma (282), and even increase the levels of PD-L1 in breast cancer and NSCLC cells $(283,284)$. Similarly, in BRAF mutation melanoma cells, which acquire resistance to BRAF inhibition, constitutive PD-L1 is elevated through cooperative activation of Jun (a primary target of MAPK signaling) and STAT3 (259). Induction of PD-L1 is dependent on MAPK activation in EGFR mutant NSCLC. Suppression of ERK1/2/cJun results in reduced PD-L1 expression (285). Evidences also imply the role of p65, AKT/STAT3, and JAK2/STAT1 as mediators in the regulation PD-L1 expression by EGFR signaling $(168,286,287)$. Moreover, the increased PD-L1 expression upon EGFR activation is also mediated by the AKT-mTOR pathway, inhibition of which (with rapamycin) abolishes the increased expression of PD-L1 upon EGFR activation through increasing lysosomal protein degradation (174). Remarkably, although EGFR activation was shown to increase PD-L1 expression through multiple signal pathways, a controversial correlation between EGFR activation mutations and PD-L1 expression was observed in NSCLC patients $(256,288-290)$, which may be attributed to the complicated regulation of PD-L1 expression (inducible and constitutive) in vivo. Therefore, despite how EGFR mutations upregulate the constitutive expression of PD-L1 in tumor cells, the concomitant shortage of activated tumor infiltrating lymphocytes in EGFR-mutated NSCLC $(291,292)$ may weaken the inducible PD-L1 expression. Recent studies have shielded light on the divergent effect of various subtypes of EGFR mutations on PD-L1 expression and the response to immune checkpoint therapy $(293,294)$. Thus, the discrepancies in PD-L1 expression caused by EGFR mutations may also result from the undistinguished subtypes of EGFR mutations.

The PI3K-AKT-mTOR signaling is another oncogenic pathway involved in constitutive regulation of $\mathrm{PD}-\mathrm{L} 1$, which can both be activated by PIK3CA mutation and functional loss of PTEN (a negative regulatory of PI3K-AKT signaling) (295). In human glioma and CRC cells, loss of PTEN activates PI3K signaling, which leads to an elevation of PD-L1 expression (296, 297). A positive correlation between PIK3CA mutation and PD-L1 expression in squamous cell lung carcinoma was also revealed (298). Nevertheless, similar to the MEK inhibition, the influence of PI3K/AKT inhibition on PD-L1 expression varies in tumor cells and the mechanism is largely unknown 
(299). Phosphorylation activation of S6K1 or inhibition of eIF4E-binding proteins (4E-BP, a negative regulator for eIF4E), which serve as the downstream effect for the activation of PI3K-AKT-mTOR pathway, are involved in the promotion of protein synthesis. Overexpression of S6K1, but not eIF4E, restores the translational efficiency of PD-L1, which is inhibited by ectopic expression of PTEN in U87 cells (a glioma cell lines with no PTEN expressed) through increased recruitment of PD-L1 transcript to the polysome. In line with this finding, rapamycin, an mTOR inhibitor, was shown to pose as an obstacle for polysomal component recruitment in PD-L1 transcripts (296). Interestingly, in a recent study carried out by Cerezo et al. (299), inhibition of eIF4F complex (consisting eIF4A, eIF4E, and eIF4G subunits) was shown to upregulate IFN- $\gamma$-induced PD-L1 expression by thwarting the translation of STAT1 mRNA in melanoma, and the upstream regulator for the signaling remains to be identified. Additionally, NPM-ALK or EML4-ALK fusion protein constitutively activates ALK kinase and promotes PD-L1 expression via MEK-ERK and PI3K-AKT signaling pathways (300, 301).

Yes-associated protein/WW domain-containing transcription regulator 1 (YAP/TAZ), the well-known effectors in the Hippo pathway, are commonly dysregulated in cancers (302). Overexpression of YAP/TAZ has been found in many cancers due to abnormal amplification, loss of Hippo signaling by mutation, and/or downregulation of the core Hippo component (303). Recent publications supported the notion that YAP/TAZ emerges as a pivotal player in tumor immunity by regulating PDL1 expression. YAP/TAZ interacting with the $P D-L 1$ promoter through the TEA domain transcription factor (TEAD) family of transcription factors enhances PD-L1 at the transcriptional level in human malignant pleural mesothelioma, melanoma, breast and lung cancer cells (304-309). Furthermore, in tumor tissues of NSCLC and melanoma, immunohistochemistry showed significantly positive staining for YAP and PD-L1 $(305,307)$. The role of the Hippo pathway in upregulating PD-L1 was further confirmed in breast and lung cancer cells as mammalian STE20like kinase 1 and 2 (MST1/2) and large tumor suppressor 1 and 2 (LATS1/2), upstream kinases and inhibitors of canonical Hippo pathway are shown to suppress PD-L1 expression (306).

\section{The Role of Tumor Suppressors}

In addition to the involvement of oncogenes in the regulation of PD-L1, tumor suppressors also play a role in controlling PD-L1 expression. Tp53, also known as p53, is a well-known tumor suppressor and commonly mutated in cancer (310). As a transcription factor, $\mathrm{p} 53$ regulates the expression of numerous downstream target genes involved in cell cycle progression, cell death, and metabolism $(311,312)$. Increasing evidence for p53 in regulating immune responses made it intriguing for researchers $(313,314)$. P53 regulates immune responses by targeting immune checkpoints, including PD-L1. The effect of p53 on PD-L1 expression is likely to be mediated by several p53-regulated miRNAs. Cortez et al. (120) revealed that p53 decreases PD-L1 expression via upregulating miR-34 in NSCLC. A recent study showed that the miR-200 family, another miRNA cluster regulated by p53 (315), downregulates
PD-L1 by directly targeting $3^{\prime}$-UTR in HCC, AML and NSCLC cells (114-116). In addition, p53 and PD-L1 expression are inversely correlated in hepatocellular carcinoma and NSCLC patients $(120,316)$. Coincidently, inactive mutation of p53 is associated with elevated PD-L1 level in lung adenocarcinoma and ovarian cancer (317-319). However, paradoxical results were also found by researchers, indicating an ambivalent role of p53 in PD-L1 regulation. MiR-18a increases PD-L1 levels by targeting SOX6 (p53 pathway activator) to inhibit p53 signaling in cervical cancer (104), and nutlin-3a, a small molecule activator of wild-type p53, enhances the expression of PDL1 in breast cancer (320). Moreover, a high rate of PD-L1 expression was observed in $\mathrm{p} 53$-positive primary pulmonary lymphoepithelioma-like carcinoma patients, compared to the p53-negative group (321).

Tumor suppressor gene PTEN is one of the most frequently mutated genes in human cancers (322). PTEN acts as a tumor suppressor through the action of its phosphatase protein product, which catalytically dephosphorylates phosphatidylinositol(3,4,5)-trisphosphate (PIP3) converted to phosphatidylinositol(4,5)bisphosphate (PIP2) (323). The enzymatic activity of PTEN further modulates PD-L1 expression through the PI3K/AKT pathway $(174,296,297,324)$. In these studies, loss or knockdown of PTEN leads to the activation of the PI3K/AKT pathway, and hence, upregulation of PD-L1. In glioma, loss of PTEN function upregulates PD-L1 expression at the translational level through AKT-mTOR-S6K1 signal axis (296). In CRC, miR-20b, miR-21, and miR-130b inhibit PTEN, resulting in PD-L1 overexpression (99). A similar effect of miR-18a was revealed in cervical cancer (104). In contrast to the findings in CRC and cervical cancer, miR-142-5p was reported to promote antitumor immunity in NSCLC by suppressing PD-L1 protein expression via the PTEN pathway (100). Loss of PTEN cytoplasmic expression is related to lower PD-L1 expression in DLBCL with AKT hyperactivation (325), suggesting that mechanisms unrelated to AKT may also be involved in PD-L1 expression in cells with different PTEN status.

Strikingly, concurrent TP53 and PTEN deletion facilitates the formation of undifferentiated pleomorphic sarcomas, with elevated PD-L1 expression, that induced immune tolerance in C57BL/6J mice (326). Simultaneous loss of PTEN and LKB1 (a tumor suppressor, also known as serine-threonine kinase 11) contributes to the development of murine lung squamous cell carcinoma with higher PD-L1 expression, while PD-L1 in the tumor is not induced by individual deficiency of either PTEN or LKB1 (327). Likewise, concomitant knockout of Kelch-like ECH-associated protein 1 (KEAP1) and PTEN in the mouse lung promotes the occurrence of adenocarcinoma with altered immune microenvironment exhibiting increased expression of PD-L1 (328). Tumor suppressor candidate 2 (TUSC2, also known as FUS1) represents another suppressor in controlling PDL1 by recent work. TUSC2 overexpression was observed to decrease PD-L1 expression and associate with an immunologic response $(329,330)$. TUSC2 was shown to negate the kinase activity of EGFR, AKT, and mTOR according to previous studies $(331,332)$. Indeed, the reduction of PD-L1 expression 
in NSCLC cell lines by TUSC2 is likely due to reduced mTOR activity (330).

The retinoblastoma protein (RB), a well-acknowledged tumor suppressor, acts as a multifunctional protein to regulate various aspects of cellular activities and tumor development $(333,334)$. Transcription factor E2F1 is a major target for RB to exhibit its tumor suppression efficacy, un- or hypophosphorylated RB binds to E2F1, leading to the inhibited expression of E2F1 target genes and arrested G1/S cell cycle transition. However, during a normal cell cycle, RB transforms into hyperphosphorylated status, mediated by cyclin/CDK complexes such as CYCLIN D/CDK4/6 in the late G1 phase, which contributes to the release of E2F1 and advance of the cell cycle (335). Interestingly, an E2F1-independent tumor suppression effect of phosphorylated RB has been unveiled by Jin et al. (336), and it is said that CDK4/6 mediated phosphorylation of RB at S249/T252 enhances its interaction with NF-KB p65 within nucleus and reduces the expression of NF- $\mathrm{KB}$ target genes, including PD-L1. RL-S249/T252D, a small phosphomimetic peptide of $R B$, is able to inhibit tumor growth in immune-proficient mice, and the regression of tumor may be partly attributed to the blocked expression of PD-L1 by RL-S249/T252D. Finally, mutations of the breast cancer type 1 and 2 susceptibility $(B R C A 1 / 2)$ genes, that are associated with familial breast cancer and ovarian cancer, were documented to be involved in immune dysfunction $(337,338)$. The observation of increased expression of PD-L1 in BRCA1/2-mutated ovarian cancer implies a possible role of BRCA1/2 for PD-L1 regulation, although the underlying mechanism remains to be explored $(319,338,339)$.

\section{The Role of Post-translational Modifications in PD-L1 Expression}

PD-L1 protein can be phosphorylated, ubiquitinated, and glycosylated after translation. These post-translational modifications (PTMs) collaboratively or competitively regulate the level of PD-L1 in cells.

The potential phosphorylation sites of PD-L1 have been predicted using the PhosphoSite database (PhosphoSite Plus Protein Page: Pd-L1 Human, 2018). However, in spite of this, the phosphorylation of PD-L1 has been sparsely reported. Horita et al. (340) identified atyrosine phosphorylation of PDL1 induced by EGF, through a set of high-affinity and highspecificity post-translational modification enrichment tools, with no specific mechanism or mediator described. Only very recently, studies have started to shine light on the regulators for phosphorylation modification of PD-L1. Glycogen synthase kinase $3 \beta$ (GSK3 $\beta$ ) was shown to phosphorylate PD-L1 and an evolutionarily conserved GSK3 $\beta$ phosphorylation motif (S/TXXXS/T) at T180 and S184 was found in PD-L1 (173). Another serine/threonine protein kinase AMP-activated protein kinase (AMPK), a sensor of cellular energy, was latterly revealed to directly phosphorylate PD-L1 at S195 (341). Both AMPKand GSK3 $\beta$-mediated phosphorylation of PD-L1 reduce the expression of PD-L1 via increasing its degradation, and disparate mechanisms were exploited to this end. Phosphorylation of PD-L1 at S195 by AMPK activation induces abnormal endoplasmic reticulum (ER) mannose trimming and produces aberrant glycoprotein of PD-L1 with mannose-rich glycan structures, which triggers the ER-associated degradation of PD-L1 (341). In contrast, GSK3 $\beta$-mediated phosphorylation often facilitates ubiquitin E3 ligase recognition, which targets proteins to proteasomal degradation $(342,343)$. Thus, GSK3 $\beta$ phosphorylates non-glycosylated PD-L1 and further initiates the interaction of PD-L1 with $\beta$-TrCP to form a complex, leading to the poly-ubiquitination of PD-L1. Furthermore, enhanced PDL1 expression, induced by EGF stimulation, may be attributed to its effect on inhibiting GSK3 $\beta$-mediated phosphorylation and poly-ubiquitination of non-glycosylated PD-L1 (173). EGF is also involved in upregulating the ubiquitination of glycosylated PD-L1, and the ubiquitination of glycosylated PDL1 is identified to be mono- and multi-ubiquitnation, but not poly-ubiquination (340). In contrast to GSK3 $\beta$ induced polyubiquitination of non-glycosylated PD-L1, that promotes its degradation via the proteasome pathway, EGF-stimulated monoand multi-ubiquitination of glycosylated PD-L1 has yielded PDL1 overexpression, as blocking the enzyme activity of ubiquitin E1 decreases PD-L1 mono- and multi-ubiquitination coupled with reduced PD-L1 level (340). The cooperative regulation of non-glycosylated and glycosylated PD-L1 induced by EGF may collaboratively increase the level of PD-L1. In a recent study, ubiqutin $\mathrm{E} 3 \mathrm{Cbl}-\mathrm{b} / \mathrm{c}-\mathrm{Cbl}$ was revealed to be negatively correlated with PD-L1 expression in EGFR wild-type NSCLC (344). Similarly, in cervical and breast cancer cells, cyclin D1-CDK4 kinase was reported to destabilize PD-L1 and increase TILs via phosphorylating cullin 3 -speckle type $\mathrm{POZ}$ protein $\left(\mathrm{CUL}^{\mathrm{SPOP}}\right)$ E3 ligase, leading to the ubiquitination of PD-L1 $(345,346)$. DCUN1D1, a regulator of ubiquitin E3 activity, was significantly increased in NSCLC tumor tissues and positively associated with PD-L1 expression, which leads to enhanced tumor metastasis and poor prognosis of the patients (347). Moreover, a ubiquitously expressed type- 3 transmembrane protein, CKLFlike MARVEL transmembrane domain containing protein 6 (CMTM6), was recently identified as a novel positive regulator of PD-L1 via increasing its half-life, which is presumably due to the reduction of ubiquitination and prevention of lysosomemediated degradation during protein recycling (348-350). Notably, this function is shared by its closest family member, CMTM4 (349). In CRC, huntingtin-interacting protein 1-related protein (HIP1R), a newly discovered regulator of PD-L1, was found to promote lysosome-mediated degradation of PD-L1 by directly binding and transporting it to lysosome via the lysosomal sorting motif of HIP1R (351). Finally, in addition to the transcriptional regulation of PD-L1, TNF- $\alpha$-mediated nuclear translocation and downstream transactivation of p65 increase PD-L1 expression by transcriptionally upregulating CSN5, which functionally hydrolyzes the ubiquitin chain from ubiquitin-PDL1 and further enhances the PD-L1 stabilization in breast cancer cells $(167,186)$.

PD-L1 is a $\sim 33 \mathrm{kDa}$ type- 1 transmembrane protein. However, detection of PD-L1 by immunoblotting revealed heterogeneous expression patterns on SDS-PAGE, and the high molecular weight of PD-L1 displays $\sim 15-\mathrm{kDa}$ molecular weight shift 
down by glycosylation inhibitors, suggesting that PD-L1 is highly glycosylated in human tumor tissues and cancer cell lines. Further studies identified that the type of glycosylation is primarily $\mathrm{N}$-glycosylation rather than O-glycosylation since glycosylation of PD-L1 was completely inhibited by $\mathrm{N}$-linked glycosylation inhibitor tunicamycin (TM) but not O-glycosidase (173). N-glycosylation occurred on the asparagine residue of an Asn-X-Ser/Thr motif ( $\mathrm{X}$ is any amino acid except proline) in protein and is catalyzed by oligosaccharyltransferase, acting as a biosynthetic secretory pathway in ER and Golgi apparatus (352, 353). Amino-acid sequence comparation across different species identifies four evolutionarily conserved NXT motifs (N refers to Asn) in PD-L1 extracelluar domain and exclusive $\mathrm{N}$-glycosylation of PD-L1 at N35, N192, N200, and N219 is further demonstrated by mass spectrometry and mutagenesis assays. Furthermore, N-glycosylations on the N192, N200, and N219 of PD-L1 cause a spatial hindrance for its interplay with GSK3 $\beta$ and competitively antagonize the GSK3 $\beta$-mediated phosphorylation of PD-L1, and thus contribute to PD-L1 protein stability. Additionally, glycosylation of PD-L1 appears to affect its interaction with PD-1 and T-cell-mediated cytolysis (173, 354). Increasing in the affinity for PD-1 to glycosylated PDL1 was also corroborated in another study (355). FKBP51s, a spliced isoform of $51 \mathrm{KDa}$ FK506-binding protein (FKBP51), which is a cochaperone and plays a role in immunoregulation and basic cellular processes involved in protein folding and trafficking, was shown to physically interact with the naïve $\mathrm{PD}$ L1 in the ER and catalyze PD-L1 folding, thus contribute to the glycosylation of PD-L1 in glioma as proposed by D'Arrigo et al. (225). Consistently, silencing of FKBP51s significantly reduces the level of glycosylated PD-L1 (225). Latterly, an emerging report by Maher et al. (356) demonstrated a physical association between multifunctional chaperone/scaffolding protein sigmal and early formed glycosylated PD-L1 in the ER in triple-negative

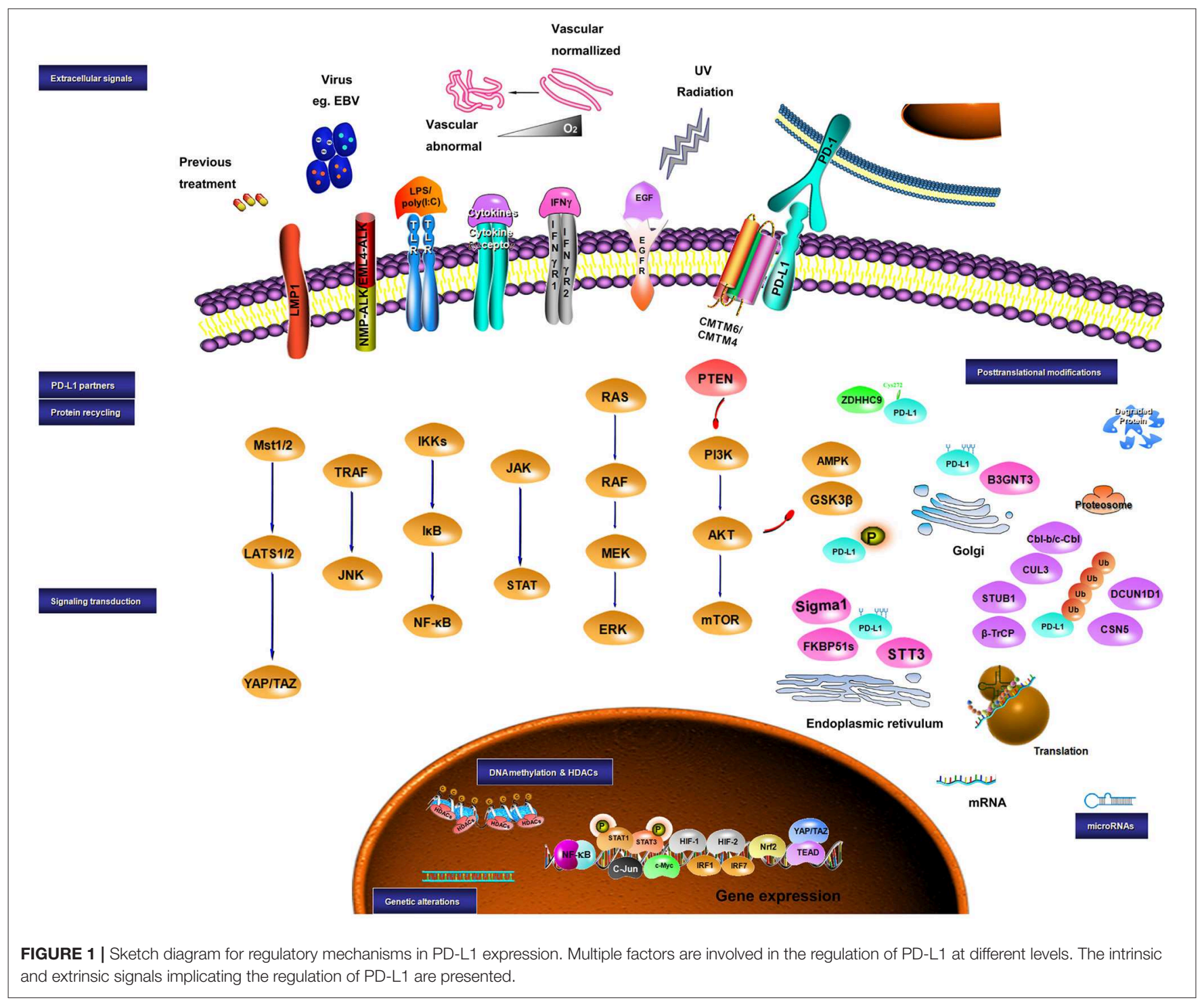


breast cancer (TNBC) and prostate cancer cells. The cooccurrence of reduced PD-L1 expression in both the intracellular membrane and plasma membrane induced by sigmal inhibition indicates that both protein stability and trafficking are involved in the regulation of PD-L1 by sigmal (356). Collectively, stabilization of PD-L1 by FKBP51s and sigmal are both related to the glycosylation process in the $\operatorname{ER}(225,356)$. Besides, dysregulation of PD-L1 glycosylation in the ER induced by AMPK activation decreases the stability of PD-L1 and triggers its ER-associated degradation (341). Furthermore, evidence has also been obtained for a possible link of EMT to PD-L1 stabilization through glycosylation regulation. EMT transcriptionally upregulates the $\mathrm{N}$-glycosyltransferase STT3 through $\beta$-catenin, and subsequently induces STT3-dependent PD-L1 N-glycosylation (193). Strikingly, the latest results have proven that glycosylated PD-L1 could serve as valuable therapeutic target for cancer (341, 354, 357). Eradication of triple-negative breast cancer cells can be achieved by treatment with STM108-MMAE, a drug-conjugated antibody specifically targeted to glycosylated PD-L1, via promoting PDL1 internalization and lysosomal degradation $(354,357)$. Owing to the aberrant glycosylation of PD-L1 in the ER, mediated by metformin, the combination of anti-CTLA 4 antibody and metformin successfully invigorates a potent anti-cancer effect and enhances tumor elimination compared to the monotherapy in a syngeneic mouse model of melanoma, breast, and colon cancer (341).

Besides the post-translational modifications mentioned above, protein lipidations, such as prenylation, myristylation, and palmitoylation, are another prevalent type of posttranslational modification. Among them, palmitoylation (also known as S-acylation) is quite different due to its reversible feature and may serve as a therapeutic target for diseases, including tumor (358). Palmitoylation is proven to play a pivotal role in regulating protein traffic, membrane localization, and interaction (359). Palmitoylated proteins also display altered protein stability and signal transduction (358-360). Since the discovery of palmitoylation modification of proteins, it has been revealed that nearly 1,000 proteins can be palmitoylated in human beings (361). Intriguingly, a single palmitoylation site at Cys272 of PD-L1, which is located in cytosolic domain, has been unveiled based on online prediction (csspalm.biocuckoo.org) and further verified by acyl-biotin exchange assays combined with mutation (362). Palmitoylation of PD-L1 in tumor cells contributes to its increased stability and avoidance of immune surveillance. It is believed that palmitoylation can spontaneously occur in vitro, and in vivo, it is usually catalyzed by protein acyltransferases (PATs). Although palmitoylation has been discovered for a long time, related PATs were identified much later $(363,364)$. Most PATs that mediated protein palmitoylation belong to the zinc finger protein family and possess a conserved Asp-His-His-Cys (DHHC) domain (364). In the study by Yang et al. (362), palmitoyltransferase ZDHHC9 was demonstrated to be responsible for the palmitoylation of PD-L1. The interaction between ZDHHC9 and PD-L1 is affirmed, knockdown of ZDHHC9 in cancer cells induces a significant reduction of PD-L1 palmitoylation and sensitizes T-cell-mediated killing, hence inhibiting tumor growth. This study raises a possible approach for targeting $\mathrm{PD}-\mathrm{L} 1$ palmitoylation to restore the immune surveillance and cytolytic activity of $\mathrm{T}$ cells for cancer treatment. This was further demonstrated by Yao et al. recently (365). In contrast to the findings in breast cancer, Yao et al. have identified palmitoyltransferase ZDHHC3 (DHHC3) as the main acyltransferase required for the palmitoylation of PD-L1 in CRC cells, inhibition of which by 2-bromopalmitate and a synthetic peptide successfully decreases PD-L1 expression and enhances T-cell immunity against the tumors.

PTMs may affect the conformation, activity, and interactions of proteins. Although the PTMs, e.g., glycosylation, phosphorylation, ubiquitination, and palmitoylation of PDL1, have been reported to influence its expression, the possible effects of these PTMs on the conformation and molecular interactions of $\mathrm{PD}-\mathrm{L} 1 / \mathrm{PD}-1$ remain rather limited. $\mathrm{PD}-\mathrm{L} 1$ can also be acetylated and SUMOylated in response to EGF (340). Thus, to fully understand the role of PTMs in PD-L1 regulation, more studies are needed to (1) characterize the types of PTMs of PD-L1, (2) decode the modification sites and the functional consequences of PTMs, (3) clarify the interactions among these PTMs, (4) evaluate the availability of PD-L1 PTMs as potential targets in PD-1/PD-L1 axis for cancer treatment.

Collectively, the expression of $\mathrm{PD}-\mathrm{L} 1$ is controlled by both intrinsic and extrinsic signaling, which may share similar molecular mechanisms. Crosstalk among these signaling pathways also plays a role in PD-L1 expression $(184,366)$. In summary, the level of PD-L1 in a tumor can be modulated by the genomic aberrances, epigenetic alterations, and extracellular stimuli in a very complex way, which may mechanistically work through transcriptional control, mRNA stability, oncogenic signaling pathway, and protein stability (Figure 1).

\section{SUMMARY}

Despite considerable improvement of cancer therapy, which has been achieved through PD-1/PD-L1 blockade, the knowledge regarding the biology of these regulators in cancer immune surveillance is still relatively limited. Many mechanisms have been revealed to regulate the expression of PD-L1 including genetic alterations, epigenetic modifiers, extracellular stimulations, signaling pathways, transcriptional factors, and post-transcriptional modulators. Generally, PD-L1 on tumor cells is regulated with two patterns: inducible and constitutive expression. Inducible expression of PD-L1 by the inflamed microenvironment within a tumor or by previous treatments may portend a better response to anti-PD-1/PD-L1 therapies and provide an opportunity for overcoming acquired resistance to prior treatments. Uncovering the mechanisms of constitutive PD-L1 expression driven by oncogenic signaling is valuable for developing new strategies for cancer therapy through directly targeting PD-L1 $(269,299)$. Similarly, synthetic peptides that either target PD-L1 degradation or post-translational modifications have shown a strong efficiency in animal studies, 
which may serve as a novel therapy for cancer treatment $(351,365)$. Notably, this kind of therapy that directly targets PD-L1 is of great significance and may be more effective as compared with blockade of PD-1/PD-L1 axis due to PD-1independent functions of PD-L1 in the promotion of malignant phenotypes and drug resistance $(367,368)$. Altogether, an extensive understanding of the mechanisms by which PD-L1 is governed will help us to reach a comprehensive evaluation of PD-1/PD-L1 targeting therapy, and further potentiate the efficacy and expand the usage of this kind of cancer therapy via patient selection and rational combination with other antineoplastic agents, as well as develop new effective strategies for cancer immunotherapy.

\section{REFERENCES}

1. Robert C, Long GV, Brady B, Dutriaux C, Maio M, Mortier L, et al. Nivolumab in previously untreated melanoma without BRAF mutation. $N$ Engl J Med. (2015) 372:320-30. doi: 10.1056/NEJMoa1412082

2. Weber JS, D’Angelo SP, Minor D, Hodi FS, Gutzmer R, Neyns B, et al. Nivolumab versus chemotherapy in patients with advanced melanoma who progressed after anti-CTLA-4 treatment (CheckMate 037): a randomised, controlled, open-label, phase 3 trial. Lancet Oncol. (2015) 16:375-84. doi: 10.1016/S1470-2045(15)70076-8

3. Garon EB, Rizvi NA, Hui R, Leighl N, Balmanoukian AS, Eder JP, et al. Pembrolizumab for the treatment of non-small-cell lung cancer. $N$ Engl J Med. (2015) 372:2018-28. doi: 10.1056/NEJMoa1501824

4. Antonia SJ, Villegas A, Daniel D, Vicente D, Murakami S, Hui R, et al. Durvalumab after chemoradiotherapy in stage III non-small-cell lung cancer. N Engl J Med. (2017) 377:1919-29. doi: 10.1056/NEJMoa1709937

5. Fehrenbacher L, von Pawel J, Park K, Rittmeyer A, Gandara DR, Ponce Aix $S$, et al. Updated efficacy analysis including secondary population results for OAK: a randomized phase III study of atezolizumab vs docetaxel in patients with previously treated advanced non-small cell lung cancer. J Thorac Oncol. (2018) 13:1156-70. doi: 10.1016/j.jtho.2018.04.039

6. Motzer RJ, Rini BI, McDermott DF, Redman BG, Kuzel TM, Harrison MR, et al. Nivolumab for metastatic renal cell carcinoma: results of a randomized phase II trial. J Clin Oncol. (2015) 33:1430-7. doi: 10.1200/JCO.2014.59.0703

7. Meti N, Esfahani K, Johnson NA. The role of immune checkpoint inhibitors in classical Hodgkin lymphoma. Cancers. (2018) 10:E204. doi: 10.3390/cancers10060204

8. Ansell SM, Lesokhin AM, Borrello I, Halwani A, Scott EC, Gutierrez M, et al. PD-1 blockade with nivolumab in relapsed or refractory Hodgkin's lymphoma. N Engl J Med. (2015) 372:311-9. doi: 10.1056/NEJMoa14 11087

9. Powles T, Eder JP, Fine GD, Braiteh FS, Loriot Y, Cruz C, et al. MPDL3280A (anti-PD-L1) treatment leads to clinical activity in metastatic bladder cancer. Nature. (2014) 515:558-62. doi: 10.1038/nature13904

10. Plimack ER, Bellmunt J, Gupta S, Berger R, Chow LQ, Juco J, et al. Safety and activity of pembrolizumab in patients with locally advanced or metastatic urothelial cancer (KEYNOTE-012): a non-randomised, open-label, phase 1b study. Lancet Oncol. (2017) 18:212-20. doi: 10.1016/S1470-2045(17) 30007-4

11. Larkins E, Blumenthal GM, Yuan W, He K, Sridhara R, Subramaniam S, et al. FDA approval summary: pembrolizumab for the treatment of recurrent or metastatic head and neck squamous cell carcinoma with disease progression on or after platinum-containing chemotherapy. Oncologist. (2017) 22:873-8. doi: 10.1634/theoncologist.2016-0496

12. Chow LQM, Haddad R, Gupta S, Mahipal A, Mehra R, Tahara M, et al. Antitumor activity of pembrolizumab in biomarker-unselected patients with recurrent and/or metastatic head and neck squamous cell carcinoma: results from the phase Ib KEYNOTE-012 expansion Cohort. (2016) 34:3838-45. doi: $10.1200 /$ JCO.2016.68.1478

\section{AUTHOR CONTRIBUTIONS}

XS wrote the manuscript. Z-XX contributed to the conception and writing. JL drew the tables and created the figure in the manuscript. LZ, YL, and YW revised the manuscript. All authors read and approved the final manuscript.

\section{FUNDING}

This work was supported by the National Natural Science Foundation of China (Nos. 81573087 and 81772924) and International Cooperation Foundation of Jilin Province (20190701006GH).

13. Nivolumab doubles survival for patients with HNSCC. Cancer Discov. (2016) 6:OF3. doi: 10.1158/2159-8290.CD-NB2016-049

14. D’Angelo SP, Russell J, Lebbé C, Chmielowski B, Gambichler T, Grob JJ, et al. Efficacy and safety of first-line avelumab treatment in patients with stage IV metastatic merkel cell carcinoma: a preplanned interim analysis of a clinical trial. JAMA Oncol. (2018) 4:e180077. doi: 10.1001/jamaoncol.2018.0077

15. Powles T, O’Donnell PH, Massard C, Arkenau HT, Friedlander TW, Hoimes CJ, et al. Efficacy and safety of durvalumab in locally advanced or metastatic urothelial carcinoma: updated results from a phase 1/2 open-label study. JAMA Oncol. (2017) 3:e172411. doi: 10.1001/jamaoncol.2017.2411

16. Le DT, Uram JN, Wang H, Bartlett BR, Kemberling H, Eyring AD, et al. PD1 blockade in tumors with mismatch-repair deficiency. N Engl J Med. (2015) 372:2509-20. doi: 10.1056/NEJMoa1500596

17. Le DT, Durham JN, Smith KN, Wang H, Bartlett BR, Aulakh LK, et al. Mismatch repair deficiency predicts response of solid tumors to PD-1 blockade. Science. (2017) 357:409-13. doi: 10.1126/science.aan6733

18. Overman MJ, McDermott R, Leach JL, Lonardi S, Lenz HJ, Morse MA, et al. Nivolumab in patients with metastatic DNA mismatch repair-deficient or microsatellite instability-high colorectal cancer (CheckMate 142): an open-label, multicentre, phase 2 study. Lancet Oncol. (2017) 18:1182-91. doi: 10.1016/S1470-2045(17)30422-9

19. Herbst RS, Soria JC, Kowanetz M, Fine GD, Hamid O, Gordon MS, et al. Predictive correlates of response to the anti-PD-L1 antibody MPDL3280A in cancer patients. Nature. (2014) 515:563-7. doi: 10.1038/nature14011

20. Gandini S, Massi D, Mandalà M. PD-L1 expression in cancer patients receiving anti PD-1/PD-L1 antibodies: a systematic review and meta-analysis. Crit Rev Oncol Hematol. (2016) 100:88-98. doi: 10.1016/j.critrevonc.2016.02.001

21. Aguiar PN Jr., De Mello RA, Hall P, Tadokoro H, Lima Lopes G. PD-L1 expression as a predictive biomarker in advanced non-small-cell lung cancer: updated survival data. Immunotherapy. (2017) 9:499-506. doi: 10.2217/imt-2016-0150

22. Chen L. Co-inhibitory molecules of the B7-CD28 family in the control of T-cell immunity. Nat Rev Immunol. (2004) 4:336-47. doi: 10.1038/nri1349

23. Townsend SE, Allison JP. Tumor rejection after direct costimulation of CD8 + T cells by B7-transfected melanoma cells. Science. (1993) 259:368-70. doi: $10.1126 /$ science.7678351

24. Walunas TL, Lenschow DJ, Bakker CY, Linsley PS, Freeman GJ, Green JM, et al. CTLA-4 can function as a negative regulator of $\mathrm{T}$ cell activation. Immunity. (1994) 1:405-13. doi: 10.1016/1074-7613(94)90071-X

25. Chen J, Jiang CC, Jin L, Zhang XD. Regulation of PD-L1: a novel role of pro-survival signalling in cancer. Ann Oncol. (2016) 27:409-16. doi: 10.1093/annonc/mdv615

26. Chen L, Han X. Anti-PD-1/PD-L1 therapy of human cancer: past, present, and future. J Clin Invest. (2015) 125:3384-91. doi: 10.1172/JCI80011

27. Blank C, Mackensen A. Contribution of the PD-L1/PD-1 pathway to T-cell exhaustion: an update on implications for chronic infections and tumor evasion. Cancer Immunol Immunother. (2007) 56:739-45. doi: $10.1007 /$ s00262-006-0272-1 
28. Iwai Y, Ishida M, Tanaka Y, Okazaki T, Honjo T, Minato N. Involvement of PD-L1 on tumor cells in the escape from host immune system and tumor immunotherapy by PD-L1 blockade. Proc Natl Acad Sci USA. (2002) 99:12293-7. doi: 10.1073/pnas.192461099

29. Keir ME, Butte MJ, Freeman GJ, Sharpe AH. PD-1 and its ligands in tolerance and immunity. Annu Rev Immunol. (2008) 26:677-704. doi: 10.1146/annurev.immunol.26.021607.090331

30. Zou W, Chen L. Inhibitory B7-family molecules in the tumour microenvironment. Nat Rev Immunol. (2008) 8:467-77. doi: 10.1038/ nri2326

31. Mazanet MM, Hughes CC. B7-H1 is expressed by human endothelial cells and suppresses T cell cytokine synthesis. J Immunol. (2002) 169:3581-8. doi: 10.4049/jimmunol.169.7.3581

32. Ishida M, Iwai Y, Tanaka Y, Okazaki T, Freeman GJ, Minato N, et al. Differential expression of PD-L1 and PD-L2, ligands for an inhibitory receptor $\mathrm{PD}-1$, in the cells of lymphohematopoietic tissues. Immunol Lett. (2002) 84:57-62. doi: 10.1016/S0165-2478(02)00142-6

33. Ingram JR, Dougan M, Rashidian M, Knoll M, Keliher EJ, Garrett S, et al. PDL1 is an activation-independent marker of brown adipocytes. Nat Commun. (2017) 8:647. doi: 10.1038/s41467-017-00799-8

34. Hino R, Kabashima K, Kato Y, Yagi H, Nakamura M, Honjo T, et al. Tumor cell expression of programmed cell death-1 ligand 1 is a prognostic factor for malignant melanoma. Cancer. (2010) 116:1757-66. doi: 10.1002/cncr.24899

35. Hamanishi J, Mandai M, Iwasaki M, Okazaki T, Tanaka Y, Yamaguchi K, et al. Programmed cell death 1 ligand 1 and tumor-infiltrating CD8 $+\mathrm{T}$ lymphocytes are prognostic factors of human ovarian cancer. Proc Natl Acad Sci USA. (2007) 104:3360-5. doi: 10.1073/pnas.0611533104

36. Mu CY, Huang JA, Chen Y, Chen C, Zhang XG. High expression of PD-L1 in lung cancer may contribute to poor prognosis and tumor cells immune escape through suppressing tumor infiltrating dendritic cells maturation. Med Oncol. (2011) 28:682-8. doi: 10.1007/s12032-010-9515-2

37. Thompson RH, Kuntz SM, Leibovich BC, Dong H, Lohse CM, Webster WS, et al. Tumor B7-H1 is associated with poor prognosis in renal cell carcinoma patients with long-term follow-up. Cancer Res. (2006) 66:3381-5. doi: 10.1158/0008-5472.CAN-05-4303

38. Butte MJ, Keir ME, Phamduy TB, Sharpe AH, Freeman GJ. Programmed death-1 ligand 1 interacts specifically with the B7-1 costimulatory molecule to inhibit $\mathrm{T}$ cell responses. Immunity. (2007) 27:111-22. doi: 10.1016/j.immuni.2007.05.016

39. Rollins MR, Gibbons Johnson RM. CD80 expressed by CD8(+) T cells contributes to PD-L1-induced apoptosis of activated CD8(+) T cells. $J$ Immunol Res. (2017) 2017:7659462. doi: 10.1155/2017/7659462

40. Matsubara T, Takada K, Azuma K, Takamori S, Toyokawa G, Haro A, et al. A clinicopathological and prognostic analysis of PD-L2 expression in surgically resected primary lung squamous cell carcinoma. Ann Surg Oncol. (2019) 26:1925-33. doi: 10.1245/s10434-019-07257-3

41. Yearley JH, Gibson C, Yu N, Moon C, Murphy E, Juco J, et al. PD-L2 expression in human tumors: relevance to anti-PD-1 therapy in cancer. Clin Cancer Res. (2017) 23:3158-67. doi: 10.1158/1078-0432.CCR-16-1761

42. George S, Papanicolau-Sengos A, Lenzo FL, Conroy JM, Nesline M, Pabla S, et al. PD-L2 amplification and durable disease stabilization in patient with urothelial carcinoma receiving pembrolizumab. Oncoimmunology. (2018) 7:e1460298. doi: 10.1080/2162402X.2018.1460298

43. Shibahara D, Tanaka K, Iwama E, Kubo N, Ota K, Azuma K, et al. Intrinsic and extrinsic regulation of PD-L2 expression in oncogenedriven non-small cell lung cancer. J Thorac Oncol. (2018) 13:926-37. doi: 10.1016/j.jtho.2018.03.012

44. Menguy S, Prochazkova-Carlotti M, Beylot-Barry M, Saltel F, Vergier B, Merlio JP, et al. PD-L1 and PD-L2 are differentially expressed by macrophages or tumor cells in primary cutaneous diffuse large B-cell lymphoma, leg type. Am J Surg Pathol. (2018) 42:326-34. doi: 10.1097/PAS.0000000000000983

45. Zhao SG, Lehrer J, Chang SL, Das R, Erho N, Liu Y, et al. The immune landscape of prostate cancer and nomination of PD-L2 as a potential therapeutic target. J Natl Cancer Inst. (2019) 111:301-10. doi: 10.1093/jnci/djy141

46. Takamori S, Takada K, Toyokawa G, Azuma K, Shimokawa M, Jogo T, et al. PD-L2 expression as a potential predictive biomarker for the response to
anti-PD-1 drugs in patients with non-small cell lung cancer. Anticancer Res. (2018) 38:5897-901. doi: 10.21873/anticanres.12933

47. Budczies J, Bockmayr M, Denkert C, Klauschen F, Gröschel S, Darb-Esfahani $\mathrm{S}$, et al. Pan-cancer analysis of copy number changes in programmed death-ligand 1 (PD-L1, CD274) - associations with gene expression, mutational load, and survival. Genes Chromosomes Cancer. (2016) 55:62639. doi: $10.1002 /$ gcc. 22365

48. Roemer MG, Advani RH, Ligon AH, Natkunam Y, Redd RA, Homer $\mathrm{H}$, et al. PD-L1 and PD-L2 genetic alterations define classical hodgkin lymphoma and predict outcome. J Clin Oncol. (2016) 34:2690-7. doi: 10.1200/JCO.2016.66.4482

49. Green MR, Monti S, Rodig SJ, Juszczynski P, Currie T, O’Donnell E, et al. Integrative analysis reveals selective 9p24.1 amplification, increased PD-1 ligand expression, and further induction via JAK2 in nodular sclerosing Hodgkin lymphoma and primary mediastinal large B-cell lymphoma. Blood. (2010) 116:3268-77. doi: 10.1182/blood-2010-05-282780

50. Budczies J, Mechtersheimer G, Denkert C, Klauschen F, Mughal SS, Chudasama P, et al. PD-L1 (CD274) copy number gain, expression, and immune cell infiltration as candidate predictors for response to immune checkpoint inhibitors in soft-tissue sarcoma. Oncoimmunology. (2017) 6:e1279777. doi: 10.1080/2162402X.2017.1279777

51. Goldmann T, Kugler C, Reinmuth N, Vollmer E, Reck M. PD-L1 copy number gain in nonsmall-cell lung cancer defines a new subset of patients for anti PD-L1 therapy. Ann Oncol. (2016) 27:206-7. doi: 10.1093/annonc/mdv510

52. Ikeda S, Okamoto T, Okano S, Umemoto Y, Tagawa T, Morodomi Y, et al. PD-L1 is upregulated by simultaneous amplification of the PD-L1 and JAK2 genes in non-small cell lung cancer. J Thorac Oncol. (2016) 11:62-71. doi: 10.1016/j.jtho.2015.09.010

53. George J, Saito M, Tsuta K, Iwakawa R, Shiraishi K, Scheel AH, et al. Genomic amplification of CD274 (PD-L1) in small-cell lung cancer. Clin Cancer Res. (2017) 23:1220-6. doi: 10.1158/1078-0432.CCR-16-1069

54. Georgiou K, Chen L, Berglund M, Ren W, de Miranda NF, Lisboa S, et al. Genetic basis of PD-L1 overexpression in diffuse large B-cell lymphomas. Blood. (2016) 127:3026-34. doi: 10.1182/blood-2015-12-686550

55. Wang W, Sun J, Li F, Li R, Gu Y, Liu C, et al. A frequent somatic mutation in CD274 3'-UTR leads to protein over-expression in gastric cancer by disrupting miR-570 binding. Hum Mutat. (2012) 33:480-4. doi: 10.1002/humu.22014

56. Wang W, Li F, Mao Y, Zhou H, Sun J, Li R, et al. A miR570 binding site polymorphism in the B7-H1 gene is associated with the risk of gastric adenocarcinoma. Hum Genet. (2013) 132:641-8. doi: 10.1007/s00439-013-1275-6

57. Tao LH, Zhou XR, Li FC, Chen Q, Meng FY, Mao Y, et al. A polymorphism in the promoter region of PD-L1 serves as a bindingsite for SP1 and is associated with PD-L1 overexpression and increased occurrence of gastric cancer. Cancer Immunol Immunother. (2017) 66:30918. doi: 10.1007/s00262-016-1936-0

58. Kataoka K, Shiraishi Y, Takeda Y, Sakata S, Matsumoto M, Nagano S, et al. Aberrant PD-L1 expression through 3'-UTR disruption in multiple cancers. Nature. (2016) 534:402-6. doi: 10.1038/nature18294

59. Kogure Y, Kataoka K. Genetic alterations in adult Tcell leukemia/lymphoma. Cancer Sci. (2017) 108:1719-25. doi: $10.1111 /$ cas. 13303

60. Wu Y, Zhao T, Jia Z, Cao D, Cao X, Pan Y, et al. Polymorphism of the programmed death-ligand 1 gene is associated with its protein expression and prognosis in gastric cancer. J Gastroenterol Hepatol. (2018). doi: 10.1111/jgh.14520. [Epub ahead of print].

61. Esteller M. Epigenetics in cancer. N Engl J Med. (2008) 358:1148-59. doi: 10.1056/NEJMra072067

62. Jones PA, Baylin SB. The fundamental role of epigenetic events in cancer. Nat Rev Genet. (2002) 3:415-28. doi: 10.1038/nrg816

63. Kim HJ, Bae SC. Histone deacetylase inhibitors: molecular mechanisms of action and clinical trials as anti-cancer drugs. Am J Transl Res. (2011) 3:166-79.

64. Karpf AR, Jones DA. Reactivating the expression of methylation silenced genes in human cancer. Oncogene. (2002) 21:5496-503. doi: 10.1038/sj.onc. 1205602 
65. Briere D, Sudhakar N, Woods DM, Hallin J, Engstrom LD, Aranda $\mathrm{R}$, et al. The class I/IV HDAC inhibitor mocetinostat increases tumor antigen presentation, decreases immune suppressive cell types and augments checkpoint inhibitor therapy. Cancer Immunol Immunother. (2018) 67:38192. doi: 10.1007/s00262-017-2091-y

66. Héninger E, Krueger TE, Lang JM. Augmenting antitumor immune responses with epigenetic modifying agents. Front Immunol. (2015) 6:29. doi: 10.3389/fimmu.2015.00029

67. Yang H, Bueso-Ramos C, DiNardo C, Estecio MR, Davanlou M, Geng QR, et al. Expression of PD-L1, PD-L2, PD-1 and CTLA4 in myelodysplastic syndromes is enhanced by treatment with hypomethylating agents. Leukemia. (2014) 28:1280-8. doi: 10.1038/leu.2013.355

68. Kim TK, Herbst RS, Chen L. Defining and understanding adaptive resistance in cancer immunotherapy. Trends Immunol. (2018) 39:624-31. doi: 10.1016/j.it.2018.05.001

69. Gevensleben H, Holmes EE, Goltz D, Dietrich J, Sailer V, Ellinger $\mathrm{J}$, et al. PD-L1 promoter methylation is a prognostic biomarker for biochemical recurrence-free survival in prostate cancer patients following radical prostatectomy. Oncotarget. (2016) 7:79943-55. doi: 10.18632/oncotarget.13161

70. Goltz D, Gevensleben H, Dietrich J, Dietrich D. PD-L1 (CD274) promoter methylation predicts survival in colorectal cancer patients. Oncoimmunology. (2016) 6:e1257454. doi: 10.1080/2162402X.2016.1257454

71. Goltz D, Gevensleben H, Grünen S, Dietrich J, Kristiansen G, Landsberg J, et al. PD-L1 (CD274) promoter methylation predicts survival in patients with acute myeloid leukemia. Leukemia. (2017) 31:738-43. doi: 10.1038/leu.2016.328

72. Micevic G, Thakral D, McGeary M, Bosenberg M. PD-L1 methylation regulates $\mathrm{PD}-\mathrm{L} 1$ expression and is associated with melanoma survival. Pigment Cell Melanoma Res. (2018) 32:435-40. doi: 10.1111/pcmr.12745

73. Chatterjee A, Rodger EJ, Ahn A, Stockwell PA, Parry M, Motwani J, et al. Marked global DNA hypomethylation is associated with constitutive PD-L1 expression in melanoma. iScience. (2018) 4:312-25. doi: 10.1016/j.isci.2018.05.021

74. Franzen A, Vogt TJ, Müller T, Dietrich J, Schröck A, Golletz C, et al. PD-L1 (CD274) and PD-L2 (PDCD1LG2) promoter methylation is associated with HPV infection and transcriptional repression in head and neck squamous cell carcinomas. Oncotarget. (2017) 9:641-50. doi: 10.18632/oncotarget.23080

75. Berghoff AS, Kiesel B, Widhalm G, Wilhelm D, Rajky O, Kurscheid S, et al. Correlation of immune phenotype with IDH mutation in diffuse glioma. Neuro Oncol. (2017) 19:1460-8. doi: 10.1093/neuonc/nox054

76. Mu L, Long Y, Yang C, Jin L, Tao H, Ge H, et al. The IDH1 mutationinduced oncometabolite. 2-hydroxyglutarate, may affect DNA methylation and expression of PD-L1 in gliomas. Front Mol Neurosci. (2018) 11:82. doi: 10.3389/fnmol.2018.00082

77. Asgarova A, Asgarov K, Godet Y, Peixoto P, Nadaradjane A, Boyer-Guittaut $\mathrm{M}$, et al. PD-L1 expression is regulated by both DNA methylation and NF-kB during EMT signaling in non-small cell lung carcinoma. Oncoimmunology. (2018) 7:e1423170. doi: 10.1080/2162402X.2017.1423170

78. Wrangle J, Wang W, Koch A, Easwaran H, Mohammad HP, Vendetti F, et al. Alterations of immune response of non-small cell lung cancer with azacytidine. Oncotarget. (2013) 4:2067-79. doi: 10.18632/oncotarget.1542

79. Lai Q, Wang H, Li A, Xu Y, Tang L, Chen Q, et al. Decitibine improve the efficiency of anti-PD-1 therapy via activating the response to IFN/PD-L1 signal of lung cancer cells. Oncogene. (2018) 37:2302-12. doi: 10.1038/s41388-018-0125-3

80. Zhang Y, Xiang C, Wang Y, Duan Y, Liu C, Zhang Y. PD-L1 promoter methylation mediates the resistance response to anti-PD-1 therapy in NSCLC patients with EGFR-TKI resistance. Oncotarget. (2017) 8:101535-44. doi: 10.18632/oncotarget.21328

81. Falkenberg KJ, Johnstone RW. Histone deacetylases and their inhibitors in cancer, neurological diseases and immune disorders. Nat Rev Drug Discov. (2014) 13:673-91. doi: 10.1038/nrd4360

82. Zhan $P$, Wang $X$, Liu $X$, Suzuki T. Medicinal chemistry insights into novel HDAC inhibitors: an updated patent review (20122016). Recent Pat Anticancer Drug Discov. (2017) 12:16-34. doi: $10.2174 / 1574892811666161101102842$
83. Zheng H, Zhao W, Yan C, Watson CC, Massengill M, Xie M, et al. HDAC inhibitors enhance T-cell chemokine expression and augment response to PD-1 immunotherapy in lung adenocarcinoma. Clin Cancer Res. (2016) 22:4119-32. doi: 10.1158/1078-0432.CCR-15-2584

84. Shen L, Ciesielski M, Ramakrishnan S, Miles KM, Ellis L, Sotomayor P, et al. Class I histone deacetylase inhibitor entinostat suppresses regulatory T cells and enhances immunotherapies in renal and prostate cancer models. PLoS ONE. (2012) 7:e30815. doi: 10.1371/journal.pone.0030815

85. Kim K, Skora AD, Li Z, Liu Q, Tam AJ, Blosser RL, et al. Eradication of metastatic mouse cancers resistant to immune checkpoint blockade by suppression of myeloid-derived cells. Proc Natl Acad Sci USA. (2014) 111:11774-9. doi: 10.1073/pnas.1410626111

86. Booth L, Roberts JL, Poklepovic A, Kirkwood J, Dent P. HDAC inhibitors enhance the immunotherapy response of melanoma cells. Oncotarget. (2017) 8:83155-70. doi: 10.18632/oncotarget.17950

87. Wang YF, Liu F, Sherwin S, Farrelly M, Yan XG, Croft A, et al. Cooperativity of HOXA5 and STAT3 Is critical for HDAC8 inhibitionmediated transcriptional activation of PD-L1 in human melanoma cells. $J$ Invest Dermatol. (2018) 138:922-32. doi: 10.1016/j.jid.2017.11.009

88. Woods DM, Sodré AL, Villagra A, Sarnaik A, Sotomayor EM, Weber J. HDAC inhibition upregulates PD-1 ligands in melanoma and augments immunotherapy with PD-1 blockade. Cancer Immunol Res. (2015) 3:137585. doi: 10.1158/2326-6066.CIR-15-0077-T

89. Lienlaf M, Perez-Villarroel P, Knox T, Pabon M, Sahakian E, Powers J, et al. Essential role of HDAC6 in the regulation of PD-L1 in melanoma. Mol Oncol. (2016) 10:735-50. doi: 10.1016/j.molonc.2015.12.012

90. Bae J, Hideshima T, Tai YT, Song Y, Richardson P, Raje N, et al. Histone deacetylase (HDAC) inhibitor ACY241 enhances anti-tumor activities of antigen-specific central memory cytotoxic $\mathrm{T}$ lymphocytes against multiple myeloma and solid tumors. Leukemia. (2018) 32:1932-47. doi: 10.1038/s41375-018-0062-8

91. Booth L, Roberts JL, Poklepovic A, Dent P. [pemetrexed + sildenafil], via autophagy-dependent HDAC downregulation, enhances the immunotherapy response of NSCLC cells. Cancer Biol Ther. (2017) 18:705-14. doi: 10.1080/15384047.2017.1362511

92. Lu C, Paschall AV, Shi H, Savage N, Waller JL, Sabbatini ME, et al. The MLL1H3K4me3 axis-mediated PD-L1 expression and pancreatic cancer immune evasion. J Natl Cancer Inst. (2017) 109:S587-89. doi: 10.1093/jnci/djw283

93. Zhu H, Bengsch F, Svoronos N, Rutkowski MR, Bitler BG, Allegrezza MJ, et al. BET bromodomain inhibition promotes anti-tumor immunity by suppressing PD-L1 expression. Cell Rep. (2016) 16:2829-37. doi: 10.1016/j.celrep.2016.08.032

94. Hogg SJ, Vervoort SJ, Deswal S, Ott CJ, Li J, Cluse LA, et al. BETbromodomain inhibitors engage the host immune system and regulate expression of the immune checkpoint ligand PD-L1. Cell Rep. (2017) 18:2162-74. doi: 10.1016/j.celrep.2017.02.011

95. Cioffi M, Trabulo SM, Vallespinos M, Raj D, Kheir TB, Lin ML, et al. The miR-25-93-106b cluster regulates tumor metastasis and immune evasion via modulation of CXCL12 and PD-L1. Oncotarget. (2017) 8:21609-25. doi: 10.18632/oncotarget.15450

96. Bartel DP. MicroRNAs: target recognition and regulatory functions. Cell. (2009) 136:215-33. doi: 10.1016/j.cell.2009.01.002

97. Tang D, Zhao D, Wu Y, Yao R, Zhou L, Lu L, et al. The miR-3127-5p/pSTAT3 axis up-regulates PD-L1 inducing chemoresistance in non-small-cell lung cancer. J Cell Mol Med. (2018) 22:3847-56. doi: 10.1111/jcmm.13657

98. Wang N, Zhang T. Down-regulation of microRNA-135 promotes sensitivity of non-small cell lung cancer to gefitinib by targeting TRIM16. Oncol Res. (2018) 26:1005-14. doi: 10.3727/096504017X15144755633680

99. Zhu J, Chen L, Zou L, Yang P, Wu R, Mao Y, et al. MiR-20b,-21, and-130b inhibit PTEN expression resulting in B7-H1 over-expression in advanced colorectal cancer. Hum Immunol. (2014) 75:348-53. doi: 10.1016/j.humimm.2014.01.006

100. Wan J, Ling X, Peng B, Ding G. miR-142-5p regulates CD4+ T cells in human non-small cell lung cancer through PD-L1 expression via the PTEN pathway. Oncol Rep. (2018) 40:272-82. doi: 10.3892/or.2018.6439

101. Zhao L, Yu H, Yi S, Peng X, Su P, Xiao Z, et al. The tumor suppressor miR138-5p targets PD-L1 in colorectal cancer. Oncotarget. (2016) 7:45370-84. doi: 10.18632/oncotarget.9659 
102. Xie WB, Liang LH, Wu KG, Wang LX, He X, Song C, et al. MiR-140 expression regulates cell proliferation and targets PD-L1 in NSCLC. Cell Physiol Biochem. (2018) 46:654-63. doi: 10.1159/000488634

103. Ji X, Wang E, Tian F. MicroRNA-140 suppresses osteosarcoma tumor growth by enhancing anti-tumor immune response and blocking mTOR signaling. Biochem Biophys Res Commun. (2018) 495:1342-8. doi: 10.1016/j.bbrc.2017.11.120

104. Dong P, Xiong Y, Yu J, Chen L, Tao T, Yi S, et al. Control of PDL1 expression by miR-140/142/340/383 and oncogenic activation of the OCT4-miR-18a pathway in cervical cancer. Oncogene. (2018) 37:5257-68. doi: 10.1038/s41388-018-0347-4

105. Naqvi AR, Fordham JB, Ganesh B, Nares S. miR-24, miR-30b and miR-142-3p interfere with antigen processing and presentation by primary macrophages and dendritic cells. Sci Rep. (2016) 6:32925. doi: $10.1038 /$ srep32925

106. Jia L, Xi Q, Wang H, Zhang Z, Liu H, Cheng Y, et al. miR-142-5p regulates tumor cell PD-L1 expression and enhances anti-tumor immunity. Biochem Biophys Res Commun. (2017) 488:425-31. doi: 10.1016/j.bbrc.2017. 05.074

107. Kao SC, Cheng YY, Williams M, Kirschner MB, Madore J, Lum T, et al. Tumor suppressor microRNAs contribute to the regulation of PD-L1 expression in malignant pleural mesothelioma. J Thorac Oncol. (2017) 12:1421-33. doi: 10.1016/j.jtho.2017.05.024

108. Yee D, Shah KM, Coles MC, Sharp TV, Lagos D. MicroRNA-155 induction via TNF- $\alpha$ and IFN- $\gamma$ suppresses expression of programmed death ligand1 (PD-L1) in human primary cells. J Biol Chem. (2017) 292:20683-93. doi: 10.1074/jbc.M117.809053

109. Jia X, Li X, Shen Y, Miao J, Liu H, Li G, et al. MiR-16 regulates mouse peritoneal macrophage polarization and affects T-cell activation. J Cell Mol Med. (2016) 20:1898-907. doi: 10.1111/jcmm.12882

110. Audrito V, Serra S, Stingi A, Orso F, Gaudino F, Bologna C, et al. PD-L1 up-regulation in melanoma increases disease aggressiveness and is mediated through miR-17-5p. Oncotarget. (2017) 8:15894-911. doi: 10.18632/oncotarget.15213

111. He B, Yan F, Wu C. Overexpressed miR-195 attenuated immune escape of diffuse large B-cell lymphoma by targeting PD-L1. Biomed Pharmacother. (2018) 98:95-101. doi: 10.1016/j.biopha.2017.11.146

112. Ahn H, Yang JM, Kim H, Chung JH, Ahn SH, Jeong WJ, et al. Clinicopathologic implications of the miR-197/PD-L1 axis in oral squamous cell carcinoma. Oncotarget. (2017) 8:66178-94. doi: 10.18632/oncotarget.19842

113. Fujita Y, Yagishita S, Hagiwara K, Yoshioka Y, Kosaka N, Takeshita F, et al. The clinical relevance of the miR-197/CKS1B/STAT3-mediated PDL1 network in chemoresistant non-small-cell lung cancer. Mol Ther. (2015) 23:717-27. doi: 10.1038/mt.2015.10

114. Sun C, Lan P, Han Q, Huang M, Zhang Z, Xu G, et al. Oncofetal gene SALL4 reactivation by hepatitis $B$ virus counteracts miR-200c in PD-L1-induced T cell exhaustion. Nat Commun. (2018) 9:1241. doi: 10.1038/s41467-018-03584-3

115. Pyzer AR, Stroopinsky D, Rosenblatt J, Anastasiadou E, Rajabi H, Washington A, et al. MUC1 inhibition leads to decrease in PDLllevels via upregulation of miRNAs. Leukemia. (2017) 31:2780-90. doi: 10.1038/leu.2017.163

116. Chen L, Gibbons DL, Goswami S, Cortez MA, Ahn YH, Byers LA, et al. Metastasis is regulated via microRNA-200/ZEB1 axis control of tumour cell PD-L1 expression and intratumoral immunosuppression. Nat Commun. (2014) 5:5241. doi: 10.1038/ncomms6241

117. Xi J, Huang Q, Wang L, Ma X, Deng Q, Kumar M, et al. miR21 depletion in macrophages promotes tumoricidal polarization and enhances PD-1 immunotherapy. Oncogene. (2018) 37:3151-65. doi: 10.1038/s41388-018-0178-3

118. Miao S, Mao X, Zhao S, Song K, Xiang C, Lv Y, et al. miR-217 inhibits laryngeal cancer metastasis by repressing AEG-1 and PD-L1 expression. Oncotarget. (2017) 8:62143-53. doi: 10.18632/oncotarget.19121

119. Boldrini L, Giordano M, Niccoli C, Melfi F, Lucchi M, Mussi $\mathrm{A}$, et al. Role of microRNA-33a in regulating the expression of PD-1 in lung adenocarcinoma. Cancer Cell Int. (2017) 17:105. doi: 10.1186/s12935-017-0474-y
120. Cortez MA, Ivan C, Valdecanas D, Wang X, Peltier HJ, Ye Y, et al. PDL1 Regulation by p53 via miR-34. J Natl Cancer Inst. (2015) 108:djv303. doi: $10.1093 /$ jnci/djv303

121. Wang Y, Wang L. miR-34a attenuates glioma cells progression and chemoresistance via targeting PD-L1. Biotechnol Lett. (2017) 39:1485-92. doi: 10.1007/s10529-017-2397-z

122. Wang X, Li J, Dong K, Lin F, Long M, Ouyang Y, et al. Tumor suppressor miR-34a targets PD-L1 and functions as a potential immunotherapeutic target in acute myeloid leukemia. Cell Signal. (2015) 27:443-52. doi: 10.1016/j.cellsig.2014.12.003

123. Wu Q, Zhao Y, Sun Y, Yan X, Wang P. miR-375 inhibits IFN- $\gamma$-induced programmed death 1 ligand 1 surface expression in head and neck squamous cell carcinoma cells by blocking JAK2/STAT1 signaling. Oncol Rep. (2018) 39:1461-8. doi: 10.3892/or.2018.6177

124. Xu S, Tao Z, Hai B, Liang H, Shi Y, Wang T, et al. miR-424(322) reverses chemoresistance via $\mathrm{T}$-cell immune response activation by blocking the PD-L1 immune checkpoint. Nat Commun. (2016) 7:11406. doi: $10.1038 /$ ncomms11406

125. Gong AY, Zhou R, Hu G, Liu J, Sosnowska D, Drescher KM, et al. Cryptosporidium parvum induces B7-H1 expression in cholangiocytes by down-regulating microRNA-513. J Infect Dis. (2010) 201:160-9. doi: $10.1086 / 648589$

126. Gong AY, Zhou R, Hu G, Li X, Splinter PL, O'Hara SP, et al. MicroRNA513 regulates $\mathrm{B} 7-\mathrm{H} 1$ translation and is involved in IFN- $\gamma$-induced B7-H1 expression in cholangiocytes. J Immunol. (2009) 182:1325-33. doi: 10.4049/jimmunol.182.3.1325

127. Wu L, Chen Z, Zhang J, Xing Y. Effect of miR-513a-5p on etoposidestimulating B7-H1 expression in retinoblastoma cells. J Huazhong Univ Sci Technolog Med Sci. (2012) 32:601-6. doi: 10.1007/s11596-012-1004-8

128. Zou MX, Guo KM, Lv GH, Huang W, Li J, Wang XB, et al. Clinicopathologic implications of CD8 $(+) / F o x p 3(+)$ ratio and miR-574-3p/PD-L1 axis in spinal chordoma patients. Cancer Immunol Immunother. (2018) 67:209-24. doi: 10.1007/s00262-017-2080-1

129. Halvorsen AR, Sandhu V, Sprauten M, Flote VG, Kure EH, Brustugun OT, et al. Circulating microRNAs associated with prolonged overall survival in lung cancer patients treated with nivolumab. Acta Oncol. (2018) 57:1225-31. doi: 10.1080/0284186X.2018.1465585

130. Zhang XL, Xu LL, Wang F. Hsa_circ_0020397 regulates colorectal cancer cell viability, apoptosis and invasion by promoting the expression of the miR-138 targets TERT and PD-L1. Cell Biol Int. (2017) 41:1056-64. doi: $10.1002 /$ cbin. 10826

131. Mastroianni J, Stickel N, Andrlová H, Hanke K, Melchinger W, Duquesne S, et al. miR-146a controls immune response in the melanoma microenvironment. Cancer Res. (2018) 79:183-95. doi: 10.1158/0008-5472.CAN-18-1397

132. Okuma Y, Hishima T, Kashima J, Homma S. High PD-L1 expression indicates poor prognosis of HIV-infected patients with non-small cell lung cancer. Cancer Immunol Immunother. (2018) 67:495-505. doi: 10.1007/s00262-017-2103-y

133. Said EA, Al-Reesi I, Al-Riyami M, Al-Naamani K, Al-Sinawi S, Al-Balushi MS, et al. Increased CD86 but Not CD80 and PD-L1 expression on liver CD68+ cells during chronic HBV Infection. PLoS ONE. (2016) 11:e0158265. doi: 10.1371/journal.pone.0158265

134. Choschzick M, Gut A, Fink D. PD-L1 receptor expression in vulvar carcinomas is HPV-independent. Virchows Arch. (2018) 473:513-6. doi: 10.1007/s00428-018-2364-7

135. Outh-Gauer S, Alt M, Le Tourneau C, Augustin J, Broudin C, Gasne $\mathrm{C}$, et al. Immunotherapy inhead and neck cancers: a new challenge for immunologists, pathologists and clinicians. Cancer Treat Rev. (2018) 65:5464. doi: 10.1016/j.ctrv.2018.02.008

136. Severa M, Giacomini E, Gafa V, Anastasiadou E, Rizzo F, Corazzari M, et al. EBV stimulates TLR- and autophagy-dependent pathways and impairs maturation in plasmacytoid dendritic cells: implications forviral immune escape. Eur J Immunol. (2013) 43:147-58. doi: 10.1002/eji.201242552

137. Fang W, Zhang J, Hong S, Zhan J, Chen N, Qin T, et al. EBVdriven LMP1 and IFN- $\gamma$ up-regulate PD-L1 in nasopharyngeal carcinoma: implications for oncotargeted therapy. Oncotarget. (2014) 5:12189-202. doi: 10.18632 /oncotarget.2608 
138. Green MR, Rodig S, Juszczynski P, Ouyang J, Sinha P, O'Donnell E, et al. Constitutive AP-1 activity and EBV infection induce PD-L1 in Hodgkin lymphomas and posttransplant lymphoproliferative disorders: implications for targeted therapy. Clin Cancer Res. (2012) 18:1611-8. doi: 10.1158/1078-0432.CCR-11-1942

139. Bass AJ, Thorsson V, Shmulevich I, Reynolds SM, Miller M, Bernard B. The cancer genome atlas research network. Comprehensive molecular characterization of gastric adenocarcinoma. Nature. (2014) 513:202-9. doi: $10.1038 /$ nature 13480

140. Balsitis S, Gali V, Mason PJ, Chaniewski S, Levine SM, Wichroski MJ, et al. Safety and efficacy of anti-PD-L1 therapy in the woodchuck model of HBV infection. PLoS ONE. (2018) 13:e0190058. doi: 10.1371/journal.pone. 0190058

141. Park C, Cho J, Lee J, Kang SY, An JY, Choi MG, et al. Host immune response index in gastric cancer identified by comprehensive analyses of tumor immunity. Oncoimmunology. (2017) 6:e1356150. doi: 10.1080/2162402X.2017.1356150

142. Abdellatif H, Shiha G. PD-L1 expression on circulating CD34+ hematopoietic stem cells closely correlated with T-cell apoptosis in chronic hepatitis c infected patients. Int J Stem Cells. (2018) 11:78-86. doi: $10.15283 /$ ijsc17047

143. Ojiro K, Qu X, Cho H, Park JJ, Vuidepot A, Lissin N, et al. Modulation of hepatitis $\mathrm{C}$ virus-specific $\mathrm{CD} 8$ effector T-cell function with antiviral effect in infectious hepatitis C virus coculture model. J Virol. (2017) 91:e02129-16. doi: 10.1128/JVI.02129-16

144. Choi YH, Jin N, Kelly F, Sakthivel SK, Yu T. Elevation of alanine aminotransferase activity occurs after activation of the cell-death signaling initiated by pattern-recognition receptors $\gg$ but before activation of cytolytic effectors in $\mathrm{NK}$ or $\mathrm{CD} 8^{+} \mathrm{T}$ cells in the liver during acute HCV infection. PLoS ONE. (2016) 11:e0165533. doi: 10.1371/journal.pone.0165533

145. Fouad H, Raziky MS, Aziz RA, Sabry D, Aziz GM, Ewais M, et al. Dendritic cell co-stimulatory and co-inhibitory markers in chronic HCV: an Egyptian study. World J Gastroenterol. (2013) 19:7711-8. doi: $10.3748 /$ wjg.v19.i43.7711

146. Shen T, Chen X, Chen Y, Xu Q, Lu F, Liu S. Increased PD-L1 expression and $\mathrm{PD}-\mathrm{L} 1 / \mathrm{CD} 86$ ratio on dendritic cells were associated with impaired dendritic cells function in HCV infection. J Med Virol. (2010) 82:1152-9. doi: 10.1002/jmv.21809

147. Domblides C, Antoine M, Hamard C, Rabbe N, Rodenas A, Vieira T, et al. Nonsmall cell lung cancer from HIV-infected patients expressed programmed cell death-ligand 1 with marked inflammatory infiltrates. AIDS. (2018) 32:461-8. doi: 10.1097/QAD.0000000000001713

148. Muthumani K, Shedlock DJ, Choo DK, Fagone P, Kawalekar OU, Goodman J, et al. HIV-mediated phosphatidylinositol 3-kinase/serine-threonine kinase activation in APCs leads to programmed death-1 ligand upregulation and suppression of HIV-specific CD8 T cells. J Immunol. (2011) 187:2932-43. doi: 10.4049/jimmunol.1100594

149. Meier A, Bagchi A, Sidhu HK, Alter G, Suscovich TJ, Kavanagh DG, et al. Upregulation of PD-L1 on monocytes and dendritic cells by HIV-1 derived TLR ligands. AIDS. (2008) 22:655-8. doi: 10.1097/QAD.0b013e3282f4de23

150. Planès R, BenMohamed L, Leghmari K, Delobel P, Izopet J, Bahraoui E. HIV1 Tatprotein induces PD-L1 (B7-H1) expression on dendritic cells through tumor necrosis factor alpha- and toll-like receptor 4-mediated mechanisms. J Virol. (2014) 88:6672-89. doi: 10.1128/JVI.00825-14

151. Hong AM, Vilain RE, Romanes S, Yang J, Smith E, Jones D, et al. PD-L1 expression in tonsillar cancer is associated with human papillomavirus positivity and improved survival: implications for antiPD1clinical trials. Oncotarget. (2016) 7:77010-20. doi: 10.18632/oncotarget. 12776

152. Lyford-Pike S, Peng S, Young GD, Taube JM, Westra WH, Akpeng B, et al. Evidence for a role of the PD-1: PD-L1 pathway in immune resistance of HPV-associated head and neck squamous cell carcinoma. Cancer Res. (2013) 73:1733-41. doi: 10.1158/0008-5472.CAN-12-2384

153. Yang W, Song Y, Lu YL, Sun JZ, Wang HW. Increased expression of programmed death (PD)-1 and its ligand PD-L1 correlates with impaired cell-mediated immunity in high-risk human papillomavirusrelated cervical intraepithelial neoplasia. Immunology. (2013) 139:513-22. doi: $10.1111 / \mathrm{imm} .12101$
154. Ukpo OC, Thorstad WL, Lewis JSJr. B7-H1 expression model for immune evasion in human papilloma virus-related oropharyngeal squamous cell carcinoma. Head Neck Pathol. (2013) 7:113-21. doi: 10.1007/s12105-012-0406-z

155. Lin PL, Cheng YM, Wu DW, Huang YJ, Lin HC, Chen CY, et al. A combination of anti-PD-L1 mAb plus Lm-LLO-E6 vaccine efficiently suppresses tumor growth and metastasis in HPV-infected cancers. Cancer Med. (2017) 6:2052-62. doi: 10.1002/cam4.1143

156. Lipson EJ, Vincent JG, Loyo M, Kagohara LT, Luber BS, Wang H, et al. PDL1 expression in the Merkel cell carcinoma microenvironment: association with inflammation, Merkel cell polyomavirus and overall survival. Cancer Immunol Res. (2013) 1:54-63. doi: 10.1158/2326-6066.CIR-13-0034

157. Kebuchi R, Konnai S, Shirai T, Sunden Y, Murata S, Onuma M, et al. Increase of cells expressing PD-L1 in bovine leukemia virus infection and enhancement of anti-viral immune responses in vitro via PD-L1 blockade. Vet Res. (2011) 42:103. doi: 10.1186/1297-9716-42-103

158. Host KM, Jacobs SR, West JA, Zhang Z, Costantini LM, Stopford $\mathrm{CM}$, et al. Kaposi's sarcoma-associated herpesvirus increases PD-L1 and proinflammatory cytokine expression in human monocytes. MBio. (2017) 8:e00917-17. doi: 10.1128/mBio.00917-17

159. Qian Y, Deng J, Geng L, Xie H, Jiang G, Zhou L, et al. TLR4 signaling induces B7-H1 expression through MAPK pathways in bladder cancer cells. Cancer Invest. (2008) 26:816-21. doi: 10.1080/07357900801941852

160. Huang B, Zhao J, Li H, He KL, Chen Y, Chen SH, et al. Toll-like receptors on tumor cells facilitate evasion of immune surveillance. Cancer Res. (2005) 65:5009-14. doi: 10.1158/0008-5472.CAN-05-0784

161. Beswick EJ, Johnson JR, Saada JI, Humen M, House J, Dann S, et al. TLR4 activation enhances the PD-L1-mediated tolerogenic capacity of colonic CD90+ stromal cells. J Immunol. (2014) 193:2218-29. doi: 10.4049/jimmunol.1203441

162. Pulko V, Liu X, Krco CJ, Harris KJ, Frigola X, Kwon ED, et al. TLR3stimulated dendritic cells up-regulate B7-H1 expression and influence the magnitude of CD8 T cell responses to tumor vaccination. J Immunol. (2009) 183:3634-41. doi: 10.4049/jimmunol.0900974

163. Varthaman A, Moreau HD, Maurin M, Benaroch P. TLR3-induced maturation of murine dendritic cells regulates CTL responses by modulating PD-L1 trafficking. PLoS ONE. (2016) 11:e0167057. doi: 10.1371/journal.pone.0167057

164. Boes M, Meyer-Wentrup F. TLR3 triggering regulates PD-L1 (CD274) expression in human neuroblastoma cells. Cancer Lett. (2015) 361:49-56. doi: 10.1016/j.canlet.2015.02.027

165. Gilardini Montani MS, Santarelli R, Falcinelli L, Gonnella R, Granato M, DiRenzo L, et al. EBV up-regulates PD-L1 on the surface of primary monocytes by increasing ROS and activating TLR signaling and STAT3. $J$ Leukoc Biol. (2018) 104:821-32. doi: 10.1002/JLB.2A0118-029RR

166. Bi XW, Wang $\mathrm{H}$, Zhang WW, Wang JH, Liu WJ, Xia ZJ, et al. PD-L1 is upregulated by EBV-driven LMP1 through NF-kB pathway and correlates with poor prognosis in natural killer/T-cell lymphoma. J Hematol Oncol. (2016) 9:109. doi: 10.1186/s13045-0160341-7

167. Grinberg-Bleyer Y, Ghosh S. A novel link between inflammation and cancer. Cancer Cell. (2016) 30:829-30. doi: 10.1016/j.ccell.2016.11.013

168. Wintterle S, Schreiner B, Mitsdoerffer M, Schneider D, Chen L, Meyermann R, et al. Expression of the B7-related molecule B7-H1 by glioma cells: a potential mechanism of immune paralysis. Cancer Res. (2003) 63:7462-7.

169. Garcia-Diaz A, Shin DS, Moreno BH, Saco J, Escuin-Ordinas $\mathrm{H}$, Rodriguez GA, et al. Interferon receptor signaling pathways regulating PD-L1 and PD-L2 expression. Cell Rep. (2017) 19:1189-201. doi: 10.1016/j.celrep.2017.04.031

170. Kondo A, Yamashita T, Tamura H, Zhao W, Tsuji T, Shimizu $\mathrm{M}$, et al. Interferon- $\gamma$ and tumor necrosis factor-alpha induce an immunoinhibitory molecule, B7-H1, via nuclear factor-kappa B activation in blasts in myelodysplastic syndromes. Blood. (2010) 116:1124-31. doi: 10.1182/blood-2009-12-255125

171. Wang X, Yang L, Huang F, Zhang Q, Liu S, Ma L, et al. Inflammatory cytokines IL-17 and TNF- $\alpha$ up-regulate PD-L1 expression in human prostate and colon cancer cells. Immunol Lett. (2017) 184:7-14. doi: 10.1016/j.imlet.2017.02.006 
172. Quandt D, Jasinski-Bergner S, Müller U, Schulze B, Seliger B. Synergistic effects of IL-4 and TNF $\alpha$ on the induction of B7-H1 in renal cell carcinoma cells inhibiting allogeneic T cell proliferation. J Transl Med. (2014) 12:151. doi: 10.1186/1479-5876-12-151

173. Li CW, Lim SO, Xia W, Lee HH, Chan LC, Kuo CW, et al. Glycosylation and stabilization of programmed death ligand-1 suppresses T-cell activity. Nat Commun. (2016) 7:12632. doi: 10.1038/ncomms12632

174. Lastwika KJ, Wilson W III, Li QK, Norris J, Xu H, Ghazarian SR, et al. Control of PD-L1 expression by oncogenic activation of the AKT-mTOR pathway in non-small cell lung cancer. Cancer Res. (2016) 76:227-38. doi: 10.1158/0008-5472.CAN-14-3362

175. Carbotti G, Barisione G, Airoldi I, Mezzanzanica D, Bagnoli M, Ferrero S, et al. IL-27 induces the expression of IDO and PD-L1 in human cancer cells. Oncotarget. (2015) 6:43267-80. doi: 10.18632/oncotarget.6530

176. Brown JA, Dorfman DM, Ma FR, Sullivan EL, Munoz O, Wood CR, et al. Blockade of programmed death-1 ligands on dendritic cells enhances $\mathrm{T}$ cell activation and cytokine production. J Immunol. (2003) 170:1257-66. doi: 10.4049/jimmunol.170.3.1257

177. de Kleijn S, Langereis JD, Leentjens J, Kox M, Netea MG, Koenderman L, et al. IFN- $\gamma$-stimulated neutrophils suppress lymphocyte proliferation through expression of PD-L1. PLOS ONE. (2013) 8:e72249. doi: 10.1371/journal.pone.0072249

178. Schoop R, Wahl P, Le Hir M, Heemann U, Wang M, Wüthrich RP. Suppressed T-cell activation by IFN- $\gamma$-induced expression of PD-L1 on renal tubular epithelial cells. Nephrol Dial Transplant. (2004) 19:2713-20. doi: $10.1093 / \mathrm{ndt} / \mathrm{gfh} 423$

179. Noguchi T, Ward JP, Gubin MM, Arthur CD, Lee SH, Hundal J, et al. Temporally distinct PD-L1 expression by tumor and host cells contributes to immune escape. Cancer Immunol Res. (2017) 5:106-17. doi: 10.1158/2326-6066.CIR-16-0391

180. Taube JM, Anders RA, Young GD, Xu H, Sharma R, McMiller TL, et al. Colocalization of inflammatory response with B7-h1 expression in human melanocytic lesions supports an adaptive resistance mechanism of immune escape. Sci Transl Med. (2012) 4:127ra37. doi: 10.1126/scitranslmed. 3003689

181. Abiko K, Matsumura N, Hamanishi J, Horikawa N, Murakami R, Yamaguchi K, et al. IFN- $\gamma$ from lymphocytes induces PD-L1 expression and promotes progression of ovarian cancer. Br J Cancer. (2015) 112:1501-9. doi: 10.1038/bjc.2015.101

182. Platanias LC. Mechanisms of type-I- and type-II-interferon-mediated signalling. Nat Rev Immunol. (2005) 5:375-86. doi: 10.1038/nri1604

183. Bellucci R, Martin A, Bommarito D, Wang K, Hansen SH, Freeman GJ, et al. Interferon- $\gamma$-induced activation of JAK1 and JAK2 suppresses tumor cell susceptibility to NK cells through upregulation of PD-L1 expression. Oncoimmunology. (2015) 4:e1008824. doi: 10.1080/2162402X.2015.1008824

184. Gowrishankar K, Gunatilake D, Gallagher SJ, Tiffen J, Rizos H, Hersey P. Inducible but not constitutive expression of $\mathrm{PD}-\mathrm{L} 1$ in human melanoma cells is dependent on activation of NF-кB. PLoS ONE. (2015) 10:e0123410. doi: 10.1371/journal.pone.0123410

185. Dorand RD, Nthale J, Myers JT, Barkauskas DS, Avril S, Chirieleison $\mathrm{SM}$, et al. Cdk5 disruption attenuates tumor PD-L1 expression and promotes antitumor immunity. Science. (2016) 353:399-403. doi: 10.1126/science.aae0477

186. Lim SO, Li CW, Xia W, Cha JH, Chan LC, Wu Y, et al. Deubiquitination and stabilization of PD-L1 by CSN5. Cancer Cell. (2016) 30:925-39. doi: 10.1016/j.ccell.2016.10.010

187. Li N, Wang J, Zhang N, Zhuang M, Zong Z, Zou J, et al. Cross-talk between TNF- $\alpha$ and IFN- $\gamma$ signaling in induction of B7-H1 expression in hepatocellular carcinoma cells. Cancer Immunol Immunother. (2018) 67:271-83. doi: 10.1007/s00262-017-2086-8

188. Thomas DA, Massagué J. TGF- $\beta$ directly targets cytotoxic T cell functions during tumor evasion of immune surveillance. Cancer Cell. (2005) 8:369-80. doi: 10.1016/j.ccr.2005.10.012

189. Tauriello DVF, Palomo-Ponce S, Stork D, Berenguer-Llergo A, BadiaRamentol J, Iglesias $M$, et al. TGF $\beta$ drives immune evasion in genetically reconstituted colon cancer metastasis. Nature. (2018) 554:538-43. doi: $10.1038 /$ nature 25492
190. Mariathasan S, Turley SJ, Nickles D, Castiglioni A, Yuen K, Wang Y, et al. TGF $\beta$ attenuates tumour response to PD-L1 blockade by contributing to exclusion of T cells. Nature. (2018) 554:544-8.

191. Kurimoto R, Iwasawa S, Ebata T, Ishiwata T, Sekine I, Tada Y, et al Drug resistance originating from a TGF- $\beta / F G F-2$-driven epithelial-tomesenchymal transition and its reversion in human lung adenocarcinoma cell lines harboring an EGFR mutation. Int J Oncol. (2016) 48:1825-36. doi: 10.3892/ijo.2016.3419

192. Evanno E, Godet J, Piccirilli N, Guilhot J, Milin S, Gombert JM, et al. Tri-methylation of H3K79 is decreased in TGF- $\beta 1$-induced epithelialto-mesenchymal transition in lung cancer. Clin Epigenetics. (2017) 9:80. doi: 10.1186/s13148-017-0380-0

193. Hsu JM, Xia W, Hsu YH, Chan LC, Yu WH, Cha JH, et al. STT3-dependent PD-L1 accumulation on cancer stem cells promotes immune evasion. Nat Commun. (2018) 9:1908. doi: 10.1038/s41467-018-04313-6

194. Baas M, Besançon A, Goncalves T, Valette F, Yagita H, Sawitzki B, et al. TGF $\beta$ dependent expression of PD-1 and PD-L1 controls CD8(+) T cell anergy in transplant tolerance. Elife. (2016) 5:e08133. doi: 10.7554/eLife.08133

195. Lan Y, Zhang D, Xu C, Hance KW, Marelli B, Qi J, et al. Enhanced preclinical antitumor activity of $\mathrm{M7824}$, a bifunctional fusionprotein simultaneously targeting PD-L1 and TGF- $\beta$. Sci Transl Med. (2018) 10:eaan5488. doi: 10.1126/scitranslmed.aan5488

196. Knudson KM, Hicks KC, Luo X, Chen JQ, Schlom J, Gameiro SR. M7824, a novel bifunctional anti-PD-L1/TGF $\beta$ Trap fusion protein, promotes anti-tumor efficacy as monotherapy and in combination with vaccine. Oncoimmunology. (2018) 7:e1426519. doi: 10.1080/2162402X.2018.1426519

197. Strauss J, Heery CR, Schlom J, Madan RA, Cao L, Kang Z, et al. Phase I trial of M7824 (MSB0011359C), a bifunctional fusion protein targeting PD-L1 and TGF $\beta$, in advanced solid tumors. Clin Cancer Res. (2018) 24:1287-95. doi: 10.1158/1078-0432.CCR-17-2653

198. Liu Y, Ma Z, Zhao C, Wang Y, Wu G, Xiao J, et al. HIF- $1 \alpha$ and HIF- $2 \alpha$ are critically involved in hypoxia-induced lipid accumulation in hepatocytes through reducing PGC- $1 \alpha$-mediated fatty acid $\beta$-oxidation. Toxicol Lett. (2014) 226:117-23. doi: 10.1016/j.toxlet.2014.01.033

199. Krzywinska E, Stockmann C. Hypoxia, metabolism and immune cell function. Biomedicines. (2018) 6:56. doi: 10.3390/biomedicines6020056

200. Barsoum IB, Hamilton TK, Li X, Cotechini T, Miles EA, Siemens DR, et al. Hypoxia induces escape from innate immunity in cancer cells via increased expression of ADAM10: role of nitric oxide. Cancer Res. (2011) 71:7433-41. doi: 10.1158/0008-5472.CAN-11-2104

201. Barsoum IB, Smallwood CA, Siemens DR, Graham CH. A mechanism of hypoxia-mediated escape from adaptive immunity in cancer cells. Cancer Res. (2014) 74:665-74. doi: 10.1158/0008-5472.CAN-13-0992

202. Brown JM, Wilson WR. Exploiting tumour hypoxia in cancer treatment. Nat Rev Cancer. (2004) 4:437-47. doi: 10.1038/nrc1367

203. Noman MZ, Desantis G, Janji B, Hasmim M, Karray S, Dessen P, et al PD-L1 is a novel direct target of HIF- $1 \alpha$, and its blockade under hypoxia enhanced MDSC-mediated T cell activation. J Exp Med. (2014) 211:781-90. doi: 10.1084/jem.20131916

204. Cubillos-Zapata C, Avendaño-Ortiz J, Hernandez-Jimenez E, Toledano V, Casas-Martin J, Varela-Serrano A, et al. Hypoxia-induced PD-L1/PD1 crosstalk impairs T-cell function in sleep apnoea. Eur Respir J. (2017) 50:1700833. doi: 10.1183/13993003.00833-2017

205. Zhu Y, Zang Y, Zhao F, Li Z, Zhang J, Fang L, et al. Inhibition of HIF-1 $\alpha$ by PX-478 suppresses tumor growth of esophageal squamous cell cancer in vitro and in vivo. Am J Cancer Res. (2017) 7:1198-212.

206. Avendaño-Ortiz J, Maroun-Eid C, Martín-Quirós A, Toledano V, CubillosZapata C, Gómez-Campelo P, et al. PD-L1 overexpression during endotoxin tolerance impairs the adaptive immune response in septic patients via HIF1 $\alpha$. J Infect Dis. (2018) 217:393-404. doi: 10.1093/infdis/jix279

207. Koh J, Jang JY, Keam B, Kim S, Kim MY, Go H, et al. EML4-ALK enhances programmed cell death-ligand 1 expression in pulmonary adenocarcinoma via hypoxia-inducible factor (HIF)- $1 \alpha$ and STAT3. Oncoimmunology. (2015) 5:e1108514. doi: 10.1080/2162402X.2015.1108514

208. Ruf M, Moch H, Schraml P. PD-L1 expression is regulated by hypoxia inducible factor in clear cell renal cell carcinoma. Int J Cancer. (2016) 139:396-403. doi: 10.1002/ijc.30077 
209. Messai Y, Gad S, Noman MZ, Le Teuff G, Couve S, Janji B, et al. Renal cell carcinoma programmed death-ligand 1, a new direct target of hypoxiainducible factor- 2 alpha, is regulated by von hippel-lindau gene mutation status. Eur Urol. (2016) 70:623-32. doi: 10.1016/j.eururo.2015.11.029

210. Huang Y, Goel S, Duda DG, Fukumura D, Jain RK. Vascular normalization as an emerging strategy to enhance cancer immunotherapy. Cancer Res. (2013) 73:2943-8. doi: 10.1158/0008-5472.CAN-12-4354

211. Huang Y, Yuan J, Righi E, Kamoun WS, Ancukiewicz M, Nezivar $\mathrm{J}$, et al. Vascular normalizing doses of antiangiogenic treatment reprogram the immunosuppressive tumor microenvironment and enhance immunotherapy. Proc Natl Acad Sci USA. (2012) 109:17561-6. doi: 10.1073/pnas.1215397109

212. Koh YW, Han JH, Yoon DH, Suh C, Huh J. PD-L1 expression correlates with VEGF and microvessel density in patients with uniformly treated classical Hodgkin lymphoma. Ann Hematol. (2017) 96:1883-90. doi: 10.1007/s00277-017-3115-6

213. Meder L, Schuldt P, Thelen M, Schmitt A, Dietlein F, Klein S, et al. Combined VEGF and PD-L1 blockade displays synergistic treatment effects in an autochthonous mouse model of small cell lung cancer. Cancer Res. (2018) 78:4270-81. doi: 10.1158/0008-5472.CAN-17-2176

214. Socinski MA, Jotte RM, Cappuzzo F, Orlandi F, Stroyakovskiy D, Nogami $\mathrm{N}$, et al. Atezolizumab for first-line treatment of metastatic nonsquamous NSCLC. N Engl J Med. (2018) 378:2288-301. doi: 10.1056/NEJMoa1716948

215. Choueiri TK, Larkin J, Oya M, Thistlethwaite F, Martignoni M, Nathan P, et al. Preliminary results for avelumab plus axitinib as first-line therapy in patients with advanced clear-cell renal-cell carcinoma (JAVELIN Renal 100): an open-label, dose-finding and dose-expansion, phase $1 \mathrm{~b}$ trial. Lancet Oncol. (2018) 19:451-60. doi: 10.1016/S1470-2045(18)30107-4

216. McDermott DF, Huseni MA, Atkins MB, Motzer RJ, Rini BI, Escudier B, et al. Clinical activity and molecular correlates of response to atezolizumab alone or in combination with bevacizumab versus sunitinib in renal cell carcinoma. Nat Med. (2018) 24:749-57. doi: 10.1038/s41591-018-0053-3

217. Skinner HD, Giri U, Yang LP, Kumar M, Liu Y, Story MD, et al. Integrative analysis identifies a novel AXL-PI3Kinase-PD-L1 signaling axis associated with radiation resistance in head and neck cancer. Clin Cancer Res. (2017) 23:2713-22. doi: 10.1158/1078-0432.CCR-16-2586

218. Ishibashi M, Tamura H, Sunakawa M, Kondo-Onodera A, Okuyama $\mathrm{N}$, Hamada $\mathrm{Y}$, et al. Myeloma drug resistance induced by binding of myeloma B7-H1 (PD-L1) to PD-1. Cancer Immunol Res. (2016) 4:779-88. doi: 10.1158/2326-6066.CIR-15-0296

219. PD-L1 blockade maintains irradiation-mediated antitumor immunity. Cancer Discov. (2014) 4:OF16. doi: 10.1158/2159-8290.CD-RW2014-012

220. Zhang P, Liu J, Li W, Li S, Han X. Lactoferricin B reverses cisplatin resistance in head and neck squamous cell carcinoma cells through targeting PD-L1. Cancer Med. (2018) 7:3178-87. doi: 10.1002/cam4.1529

221. Jiang Z, Yang Y, Yang Y, Zhang Y, Yue Z, Pan Z, et al. Ginsenoside $\mathrm{Rg} 3$ attenuates cisplatin resistance in lung cancer by downregulating PD-L1 and resuming immune. Biomed Pharmacother. (2017) 96:378-83. doi: 10.1016/j.biopha.2017.09.129

222. Muraro E, Furlan C, Avanzo M, Martorelli D, Comaro E, Rizzo A, et al. Local high-dose radiotherapy induces systemic immunomodulating effects of potential therapeutic relevance in oligometastatic breast cancer. Front Immunol. (2017) 8:1476. doi: 10.3389/fimmu.2017.01476

223. Dovedi SJ, Adlard AL, Lipowska-Bhalla G, McKenna C, Jones S, Cheadle EJ, et al. Acquired resistance to fractionated radiotherapy can be overcome by concurrent PD-L1 blockade. Cancer Res. (2014) 74:5458-68. doi: 10.1158/0008-5472.CAN-14-1258

224. Deng L, Liang H, Burnette B, Beckett M, Darga T, Weichselbaum RR, et al. Irradiation and anti-PD-L1 treatment synergistically promote antitumor immunityin mice. J Clin Invest. (2014) 124:687-95. doi: 10.1172/JCI67313

225. D’Arrigo P, Russo M, Rea A, Tufano M, Guadagno E, Del Basso De Caro ML, et al. A regulatory role for the co-chaperone FKBP51s in PD-L1 expression in glioma. Oncotarget. (2017) 8:68291-304. doi: 10.18632/oncotarget.19309

226. Song X, Shao Y, Jiang T, Ding Y, Xu B, Zheng X, et al. Radiotherapy upregulates programmed death Ligand-1 through the pathways downstream of epidermal growth factor receptor in glioma. EBio Medicine. (2018) 28:10513. doi: $10.1016 /$ j.ebiom.2018.01.027
227. Kim HJ, Park S, Kim KJ, Seong J. Clinical significance of soluble programmed cell death ligand-1 (sPD-L1) in hepatocellular carcinoma patients treated with radiotherapy. Radiother Oncol. (2018) 129:130-5. doi: 10.1016/j.radonc.2017.11.027

228. Oweida A, Lennon S, Calame D, Korpela S, Bhatia S, Sharma J, et al. Ionizing radiation sensitizes tumors to PD-L1 immune checkpoint blockade in orthotopic murine head and neck squamous cell carcinoma. Oncoimmunology. (2017) 6:e1356153. doi: 10.1080/2162402X.2017.1356153

229. Sampath S, Won H, Massarelli E, Li M, Frankel P, Vora N, et al. Combined modality radiation therapy promotes tolerogenic myeloidcell populations and STAT3-related gene expression in head and neck cancerpatients. Oncotarget. (2018) 9:11279-90. doi: 10.18632/oncotarget.24397

230. Sato H, Niimi A, Yasuhara T, Permata TBM, Hagiwara Y, Isono M, et al. DNA double-strand break repair pathway regulates $\mathrm{PD}-\mathrm{L} 1$ expression in cancer cells. Nat Commun. (2017) 8:1751. doi: 10.1038/s41467-017-01883-9

231. Shen MJ, Xu LJ, Yang L, Tsai Y, Keng PC, Chen Y, et al. Radiation alters PDL1/NKG2D ligand levels in lung cancer cells and leads to immune escape from NK cell cytotoxicity via IL-6-MEK/Erk signaling pathway. Oncotarget. (2017) 8:80506-20. doi: 10.18632/oncotarget.19193

232. Azad A, Yin Lim S, D'Costa Z, Jones K, Diana A, Sansom OJ, et al. PD-L1 blockade enhances response of pancreatic ductal adenocarcinoma to radiotherapy. EMBO Mol Med. (2017) 9:167-80. doi: 10.15252/emmm.201606674

233. Patel KR, Martinez A, Stahl JM, Logan SJ, Perricone AJ, Ferris MJ, et al. Increase in PD-L1 expression after pre-operative radiotherapy for soft tissue sarcoma. Oncoimmunology. (2018) 7:e1442168. doi: 10.1080/2162402X.2018.1442168

234. Zhu B, Tang L, Chen S, Yin C, Peng S, Li X, et al. Targeting the upstream transcriptional activator of $\mathrm{PD}-\mathrm{L} 1$ as an alternative strategy in melanoma therapy. Oncogene. (2018) 37:4941-54. doi: 10.1038/s41388-0180314-0

235. Schutsky K, Powell Jr., Daniel J. (Perelman School of Medicine, University of Pennsylvania, Philadelphia, PA, USA). Unpublished observations: Chemotherapy and HDACi induce PD-L1 and Class I expression on ovarian cancer tumor cells. (2016).

236. Rojkó L, Reiniger L, Téglási V, Fábián K, Pipek O, Vágvölgyi A, et al. Chemotherapy treatment is associated with altered PD-L1 expression in lung cancer patients. J Cancer Res Clin Oncol. (2018) 144:1219-26. doi: 10.1007/s00432-018-2642-4

237. Qin X, Liu C, Zhou Y, Wang G. Cisplatin induces programmed death1-ligand 1 (PD-L1) over-expression in hepatoma $\mathrm{H} 22$ cells via Erk /MAPK signaling pathway. Cell Mol Biol. (2010) 56(Suppl.)OL1366-72. doi: $10.1170 / 156$

238. Tran L, Allen CT, Xiao R, Moore E, Davis R, Park SJ, et al. Cisplatin alters antitumor immunity and synergizes with PD-1/PD-L1 inhibition in head and neck squamous cell carcinoma. Cancer Immunol Res. (2017) 5:1141-51. doi: 10.1158/2326-6066.CIR-17-0235

239. Ock CY, Kim S, Keam B, Kim S, Ahn YO, Chung EJ, et al. Changes in programmed death-ligand 1 expression during cisplatin treatment in patients with head and neck squamous cell carcinoma. Oncotarget. (2017) 8:97920-7. doi: 10.18632/oncotarget. 18542

240. Suda K, Rozeboom L, Rivard CJ, Yu H, Ellison K, Melnick MAC, et al. Therapy-induced E-cadherin downregulation alters expression of programmed death ligand-1 in lung cancer cells. Lung Cancer. (2017) 109:18. doi: 10.1016/j.lungcan.2017.04.010

241. Shen M, Tsai Y, Zhu R, Keng PC, Chen Y, Chen Y, et al. FASNTGF- $\beta 1-P D-L 1$ axis contributes to the development of resistance to NK cell cytotoxicity of cisplatin-resistant lung cancer cells. Biochim Biophys Acta. (2018) 1863:313-22. doi: 10.1016/j.bbalip.2017. 12.012

242. Zhang P, Ma Y, Lv C, Huang M, Li M, Dong B, et al. Upregulation of programmed cell death ligand 1 promotes resistance response in non-smallcell lung cancer patients treated with neo-adjuvant chemotherapy. Cancer Sci. (2016) 107:1563-71. doi: 10.1111/cas.13072

243. Yan F, Pang J, Peng Y, Molina JR, Yang P, Liu S. Elevated cellular PD1/PD-L1 expression confers acquired resistance to cisplatin in small cell lung cancer cells. PLoS ONE. (2016) 11:e0162925. doi: 10.1371/journal.pone.0162925 
244. Yang M, Liu P, Wang K, Glorieux C, Hu Y, Wen S, et al. Chemotherapy induces tumor immune evasion by upregulation of programmed cell death ligand 1 expression in bone marrow stromal cells. Mol Oncol. (2017) 11:35872. doi: 10.1002/1878-0261.12032

245. Mesnage SJL, Auguste A, Genestie C, Dunant A, Pain E, Drusch F, et al. Neoadjuvant chemotherapy (NACT) increases immune infiltration and programmed death-ligand 1 (PD-L1) expression in epithelial ovarian cancer (EOC). Ann Oncol. (2017) 28:651-7. doi: 10.1093/annonc/ mdw625

246. Ghebeh H, Lehe C, Barhoush E, Al-Romaih K, Tulbah A, Al-Alwan M, et al. Doxorubicin downregulates cell surface B7-H1 expression and upregulates its nuclea rexpression in breast cancer cells: role of $\mathrm{B} 7-\mathrm{H} 1$ as an antiapoptotic molecule. Breast Cancer Res. (2010) 12:R48. doi: 10.1186/bcr2605

247. Rom-Jurek EM, Kirchhammer N, Ugocsai P, Ortmann O, Wege AK, Brockhoff G. Regulation of programmed death ligand 1 (PD-L1) expression in breast cancer cell lines in vitro and in immunodeficient and humanized tumor mice. Int J Mol Sci. (2018) 19:E563. doi: 10.3390/ijms19020563

248. Zhang $\mathrm{P}$, Su DM, Liang M, Fu J. Chemopreventive agents induce programmed death-1-ligand 1 (PD-L1) surface expression in breast cancer cells and promote PD-L1-mediated T cell apoptosis. Mol Immunol. (2008) 45:1470-6. doi: 10.1016/j.molimm.2007.08.013

249. Doi T, Ishikawa T, Okayama T, Oka K, Mizushima K, Yasuda T, et al. The JAK/STAT pathway is involved in the upregulation of PD-L1 expression in pancreatic cancer cell lines. Oncol Rep. (2017) 37:1545-54. doi: 10.3892/or.2017.5399

250. Dosset M, Vargas TR, Lagrange A, Boidot R, Végran F, Roussey A, et al. PD-1/PD-L1 pathway: an adaptive immune resistance mechanism to immunogenic chemotherapy in colorectal cancer. Oncoimmunology. (2018) 7:e1433981. doi: 10.1080/2162402X.2018.1433981

251. Gong W, Song Q, Lu X, Gong W, Zhao J, Min P, et al. Paclitaxel induced B7H1 expression in cancer cells via the MAPK pathway. J Chemother. (2011) 23:295-9. doi: 10.1179/joc.2011.23.5.295

252. Peng J, Hamanishi J, Matsumura N, Abiko K, Murat K, Baba T, et al. Chemotherapy Induces Programmed Cell Death-Ligand 1 Overexpression via the Nuclear Factor- $\mathrm{B}$ to Fosteran Immunosuppressive Tumor Microenvironment in Ovarian Cancer. Cancer Res. (2015) 75:5034-45. doi: 10.1158/0008-5472.CAN-14-3098

253. Guo Z, Wang H, Meng F, Li J, Zhang S. Combined trabectedin and antiPDlantibody produces a synergistic antitumor effect in a murine model of ovarian cancer. J Transl Med. (2015) 13:247. doi: 10.1186/s12967-015-0613-y

254. Van Der Kraak L, Goel G, Ramanan K, Kaltenmeier C, Zhang L, Normolle DP, et al. 5-Fluorouracil upregulates cell surface B7-H1 (PD-L1) expression in gastrointestinal cancers. J Immunother Cancer. (2016) 4:65. doi: 10.1186/s40425-016-0163-8

255. Shalapour S, Font-Burgada J, Di Caro G, Zhong Z, Sanchez-Lopez E, Dhar D, et al. Immunosuppressive plasma cells impede T-celldependent immunogenic chemotherapy. Nature. (2015) 521:94-8. doi: 10.1038/nature14395

256. Azuma K, Ota K, Kawahara A, Hattori S, Iwama E, Harada T, et al. Association of PD-L1 overexpression with activating EGFR mutations in surgically resected nonsmall-cell lung cancer. Ann Oncol. (2014) 25:1935-40. doi: 10.1093/annonc/mdu242

257. Jiang XM, Xu YL, Huang MY, Zhang LL, Su MX, Chen X, et al. Osimertinib (AZD9291) decreases programmed death ligand-1 in EGFRmutated non-small cell lungcancer cells. Acta Pharmacol Sin. (2017) 38:1512-20. doi: 10.1038/aps.2017.123

258. Liu L, Mayes PA, Eastman S, Shi H, Yadavilli S, Zhang T, et al. The BRAF and MEK inhibitors dabrafenib and trametinib: effects on immune function and in combination with immunomodulatory antibodies targeting PD-1, PD-L1, and CTLA-4. Clin Cancer Res. (2015) 21:1639-51. doi: 10.1158/1078-0432.CCR-14-2339

259. Jiang X, Zhou J, Giobbie-Hurder A, Wargo J, Hodi FS. The activation of MAPK in melanoma cells resistant to BRAF inhibition promotes PD-L1 expression that is reversible by MEK and PI3K inhibition. Clin Cancer Res. (2013) 19:598-609. doi: 10.1158/1078-0432.CCR-12-2731

260. Massi D, Romano E, Rulli E, Merelli B, Nassini R, De Logu F, et al. Baseline $\beta$-catenin, programmed death-ligand 1 expression and tumourinfiltrating lymphocytes predict response and poor prognosis in BRAF inhibitor-treated melanoma patients. Eur J Cancer. (2017) 78:70-81. doi: 10.1016/j.ejca.2017.03.012

261. Semaan A, Dietrich D, Bergheim D, Dietrich J, Kalff JC, Branchi V, et al. CXCL12 expression and PD-L1 expression serve as prognostic biomarkers in HCC and are induced by hypoxia. Virchows Arch. (2017) 470:185-96. doi: 10.1007/s00428-016-2051-5

262. Rice AE, Latchman YE, Balint JP, Lee JH, Gabitzsch ES, Jones FR. An HPVE6/E7 immunotherapy plus PD-1 checkpoint inhibition results in tumor regression and reduction in PD-L1 expression. Cancer Gene Ther. (2015) 22:454-62. doi: 10.1038/cgt.2015.40

263. Köhnke T, Krupka C, Tischer J, Knösel T, Subklewe M. Increase of PD-L1 expressing B-precursor ALL cells in a patient resistant to the CD19/CD3bispecific T cell engager antibody blinatumomab. J Hematol Oncol. (2015) 8:111. doi: 10.1186/s13045-015-0213-6

264. Yue C, Jiang Y, Li P, Wang Y, Xue J, Li N, et al. Dynamic change of PDL1 expression on circulating tumor cells in advanced solid tumor patients undergoing PD-1 blockade therapy. Oncoimmunology. (2018) 7:e1438111. doi: 10.1080/2162402X.2018.1438111

265. Dang CV. MYC on the path to cancer. Cell. (2012) 149:22-35. doi: 10.1016/j.cell.2012.03.003

266. Casey SC, Tong L, Li Y, Do R, Walz S, Fitzgerald KN, et al. MYC regulates the antitumor immune response through CD47 and PD-L1. Science. (2016) 352:227-31. doi: 10.1126/science.aac9935

267. Atsaves V, Tsesmetzis N, Chioureas D, Kis L, Leventaki V, Drakos E, et al. PD-L1 is commonly expressed and transcriptionally regulated by STAT3 and MYC in ALK-negative anaplastic large-cell lymphoma. Leukemia. (2017) 31:1633-7. doi: 10.1038/leu.2017.103

268. Wang J, Jia Y, Zhao S, Zhang X, Wang X, Han X, et al. BIN1 reverses PDL1-mediated immune escape by inactivating the c-MYC and EGFR/MAPK signaling pathways in non-small cell lung cancer. Oncogene. (2017) 6:623543. doi: 10.1038/onc.2017.217

269. Xu Y, Poggio M, Jin HY, Shi Z, Forester CM, Wang Y, et al. Translation control of the immune checkpoint in cancer and its therapeutic targeting. Nat Med. (2019) 25:301-11. doi: 10.1038/s41591-018-0321-2

270. Shaulian E, Karin M. AP-1 as a regulator of cell life and death. Nat Cell Biol. (2002) 4:E131-6. doi: 10.1038/ncb0502-e131

271. Sumimoto H, Takano A, Teramoto K, Daigo Y. RAS-mitogenactivated protein kinase signal is required for enhanced PD-L1 expression in human lung cancers. PLOS ONE. (2016) 1:e0166626. doi: 10.1371/journal.pone.0166626

272. Schaefer TS, Sanders LK, Nathans D. Cooperative transcriptional activity of Jun and Stat3 beta, a short form of Stat3. Proc Natl Acad Sci USA. (1995) 2:9097-101. doi: 10.1073/pnas.92.20.9097

273. Zhang X, Wrzeszczynska MH, Horvath CM, Darnell JE Jr. Interacting regions in Stat 3 and c-Jun that participate in cooperative transcriptional activation. MolCell Biol. (1999) 9:7138-46. doi: 10.1128/MCB.19.10.7138

274. Bu LL, Yu GT, Wu L, Mao L, Deng WW, Liu JF, et al. STAT3 induces immunosuppression by upregulating PD-1/PD-L1 in HNSCC. J Dent Res. (2017) 6:1027-34. doi: 10.1177/0022034517712435

275. Marzec M, Zhang Q, Goradia A, Raghunath PN, Liu X, Paessler M, et al. Oncogenic kinase NPM/ALK induces through STAT3 expression of immunosuppressive protein CD274 (PD-L1, B7-H1). Proc Natl Acad Sci USA. (2008) 05:20852-7. doi: 10.1073/pnas.0810958105

276. Concha-Benavente F, Srivastava RM, Trivedi S, Lei Y, Chandran U, Seethala RR, et al. Identification of the cell-intrinsic and -extrinsic pathways downstream of EGFR and IFN $\gamma$ that induce PD-L1 expression in head and neck cancer. Cancer Res. (2016) 76:1031-43. doi: 10.1158/0008-5472.CAN-15-2001

277. Pawlus MR, Wang L, Hu CJ. STAT3 and HIF $1 \alpha$ cooperatively activate HIF1 target genes in MDA-MB-231 and RCC4 cells. Oncogene. (2014) 3:1670-9. doi: 10.1038/onc.2013.115

278. Bouillez A, Rajabi H, Jin C, Samur M, Tagde A, Alam M, et al. MUC1-C integrates PD-L1 induction with repression of immune effectors in non-small-cell lung cancer. Oncogene. (2017) 6:4037-46. doi: 10.1038/onc.2017.47

279. Roberts PJ, Der CJ. Targeting the Raf-MEK-ERK mitogen-activated protein kinase cascade for the treatment of cancer. Oncogene. (2007) 6:3291-310. doi: $10.1038 /$ sj.onc. 1210422 
280. Coelho MA, de Carné Trécesson S, Rana S, Zecchin D, Moore C, Molina-Arcas $\mathrm{M}$, et al. Oncogenic RAS signaling promotes tumor immunoresistance by stabilizing PD-L1 mRNA. Immunity. (2017) 7:108399. doi: 10.1016/j.immuni.2017.11.016

281. Chen N, Fang W, Lin Z, Peng P, Wang J, Zhan J, et al. KRAS mutationinduced upregulation of PD-L1 mediates immune escape in human lung adenocarcinoma. Cancer Immunol Immunother. (2017) 6:1175-87. doi: 10.1007/s00262-017-2005-z

282. Atefi M, Avramis E, Lassen A, Wong DJ, Robert L, Foulad D, et al. Effects of MAPK and PI3K pathways on PD-L1 expression in melanoma. Clin Cancer Res. (2014) 20:3446-57. doi: 10.1158/1078-0432.CCR-13-2797

283. Loi S, Dushyanthen S, Beavis PA, Salgado R, Denkert C, Savas P, et al. RAS/MAPK activation is associated with reduced tumor-infiltrating lymphocytes in triple-negative breast cancer: therapeutic cooperation between MEK and PD-1/PD-L1 immune checkpoint inhibitors. Clin Cancer Res. (2016) 2:1499-509. doi: 10.1158/1078-0432.CCR-15-1125

284. Minchom A, Thavasu P, Ahmad Z, Stewart A, Georgiou A, O'Brien MER, et al. A study of PD-L1 expression in KRAS mutant non-small cell lung cancer cell lines exposed to relevant targeted treatments. PLoS ONE. (2017) 2:e0186106. doi: 10.1371/journal.pone.0186106

285. Chen N, Fang W, Zhan J, Hong S, Tang Y, Kang S, et al. Upregulation of PD-L1 by EGFR activation mediates the immune escape in EGFRdriven NSCLC: implication for optional immune targeted therapy for NSCLC patients with EGFR mutation. J Thorac Oncol. (2015) 10:910-23. doi: 10.1097/JTO.0000000000000500

286. Lin K, Cheng J, Yang T, Li Y, Zhu B. EGFR-TKI down-regulates PD-L1 in EGFR mutant NSCLC through inhibiting NF-кB. Biochem Biophys Res Commun. (2015) 63:95-101. doi: 10.1016/j.bbrc.2015.05.030

287. Zhang N, Zeng Y, Du W, Zhu J, Shen D, Liu Z, et al. The EGFR pathway is involved in the regulation of PD-L1 expression via the IL-6/JAK/STAT3 signaling pathway in EGFR-mutated non-small cell lung cancer. Int J Oncol. (2016) 9:1360-8. doi: 10.3892/ijo.2016.3632

288. Petrelli F, Maltese M, Tomasello G, Conti B, Borgonovo K, Cabiddu M, et al. Clinical and molecular predictors of PD-L1 expression in non-small-cell lung cancer: systematic review and meta-analysis. Clin Lung Cancer. (2018) 19:315-22. doi: 10.1016/j.cllc.2018.02.006

289. Roussel H, De Guillebon E, Biard L, Mandavit M, Gibault L, Fabre E, et al. Composite biomarkers defined by multiparametric immunofluorescence analysis identify ALK-positive adenocarcinoma as a potential target for immunotherapy. Oncoimmunology. (2017) 6:e1286437. doi: 10.1080/2162402X.2017.1286437

290. Rangachari D, VanderLaan PA, Shea M, Le X, Huberman MS, Kobayashi $\mathrm{SS}$, et al. Correlation between classic driver oncogene mutations in EGFR, ALK, or ROS1 and 22C3-PD-L1 $\geq 50 \%$ expression in lung adenocarcinoma. J Thorac Oncol. (2017) 12:878-3. doi: 10.1016/j.jtho.2016.12.026

291. Toki MI, Mani N, Smithy JW, Liu Y, Altan M, Wasserman B, et al. Immune marker profiling and programmed death ligand 1 expression across NSCLC mutations. J Thorac Oncol. (2018) 13:1884-96. doi: $10.1016 /$ j.jtho.2018.09.012

292. Dong ZY, Zhang JT, Liu SY, Su J, Zhang C, Xie Z, et al. EGFR mutation correlates with uninflamed phenotype and weak immunogenicity, causing impaired response to $\mathrm{PD}-1$ blockade in non-small cell lung cancer. Oncoimmunology. (2017) 6:e1356145. doi: 10.1080/2162402X.2017.1356145

293. Song P, Wu S, Zhang L, Zeng X, Wang J. Correlation between PDL1 expression and clinicopathologic features in 404 patients with lung adenocarcinoma. Interdiscip Sci. (2019). doi: 10.1007/s12539-019-00329-8

294. Hastings K, Yu H, Wei W, Sanchez-Vega F, DeVeaux M, Choi J, et al. EGFR mutation subtypes and response to immune checkpoint blockade treatment in non-small cell lung cancer. Ann Oncol. (2019). doi: 10.1093/annonc/mdz141. [Epub ahead of print].

295. Vivanco I, Sawyers CL. The phosphatidylinositol 3-Kinase AKT pathway in human cancer. Nat Rev Cancer. (2002) 2:489-501. doi: 10.1038/ nrc839

296. Parsa AT, Waldron JS, Panner A, Crane CA, Parney IF, Barry JJ, et al. Loss of tumor suppressor PTEN function increases B7-H1 expression and immunoresistance in glioma. Nat Med. (2007) 3:84-8. doi: 10.1038/ $\mathrm{nm} 1517$
297. Song M, Chen D, Lu B, Wang C, Zhang J, Huang L, et al. PTEN loss increases PD-L1 protein expression and affects the correlation between PDL1 expression and clinical parameters in colorectal cancer. PLOS ONE. (2013) 8:e65821. doi: 10.1371/journal.pone.0065821

298. McGowan M, Hoven AS, Lund-Iversen M, Solberg S, Helland $\AA$, Hirsch FR, et al. PIK3CA mutations as prognostic factor in squamous cell lung carcinoma. Lung Cancer. (2017) 103:52-7. doi: 10.1016/j.lungcan.2016.11.018

299. Cerezo M, Guemiri R, Druillennec S, Girault I, Malka-Mahieu H, Shen S, et al. Translational control of tumor immune escape via the eIF4F-STAT1-PD-L1 axis in melanoma. Nat Med. (2018). 24:1877-86. doi: 10.1038/s41591-018-0217-1

300. Yamamoto R, Nishikori M, Tashima M, Sakai T, Ichinohe T, Takaori-Kondo A, et al. B7-H1 expression is regulated by MEK/ERK signaling pathway in anaplastic large cell lymphoma and Hodgkin lymphoma. Cancer Sci. (2009) 100:2093-100. doi: 10.1111/j.1349-7006.2009.01302.x

301. Ota K, Azuma K, Kawahara A, Hattori S, Iwama E, Tanizaki J, et al. Induction of PD-L1 expression by the EML4-ALK oncoprotein and downstream signaling pathways in non-small cell lung cancer. Clin Cancer Res. (2015) 21:4014-21. doi: 10.1158/1078-0432.CCR-15-0016

302. Zanconato F, Cordenonsi M, Piccolo S. YAP/TAZ at the roots of cancer. Cancer Cell. (2016) 9:783-803. doi: 10.1016/j.ccell.2016.05.005

303. Moroishi T, Hansen CG, Guan KL. The emerging roles of YAP and TAZ in cancer. Nat Rev Cancer. (2015) 5:73-9. doi: 10.1038/nrc3876

304. Hsu PC, Miao J, Wang YC, Zhang WQ, Yang YL, Wang CW, et al. Inhibition of yes-associated protein down-regulates PD-L1 (CD274) expression in human malignant pleural mesothelioma. J Cell Mol Med. (2018) 2:3139-48. doi: $10.1111 /$ jcmm.13593

305. Kim MH, Kim CG, Kim SK, Shin SJ, Choe EA, Park SH, et al. YAP-induced PD-L1 expression drives immune evasion in BRAFi-resistant melanoma. Cancer Immunol Res. (2018) 6:255-66. doi: 10.1158/2326-6066.CIR17-0320

306. Janse van Rensburg HJ, Azad T, Ling M, Hao Y, Snetsinger B, Khanal $\mathrm{P}$, et al. The hippo pathway component TAZ promotes immune evasion in human cancer through PD-L1. Cancer Res. (2018) 8:1457-70. doi: 10.1158/0008-5472.CAN-17-3139

307. Miao J, Hsu PC, Yang YL, Xu Z, Dai Y, Wang Y, et al. YAP regulates PD-L1 expression in human NSCLC cells. Oncotarget. (2017) 8:114576-87. doi: 10.18632/oncotarget.23051

308. Lee BS, Park DI, Lee DH, Lee JE, Yeo MK, Park YH, et al. Hippo effector YAP directly regulates the expression of PD-L1 transcripts in EGFR-TKI-resistant lung adenocarcinoma. Biochem Biophys Res Commun. (2017) 91:493-9. doi: 10.1016/j.bbrc.2017.07.007

309. Feng J, Yang H, Zhang Y, Wei H, Zhu Z, Zhu B, et al. Tumor cellderived lactate induces TAZ-dependent upregulation of PD-L1 through GPR81 in human lung cancer cells. Oncogene. (2017) 6:5829-39. doi: 10.1038/onc.2017.188

310. Pfeifer GP, Holmquist GP. Mutagenesis in the P53 gene. Biochim Biophys Acta. (1997) 1333:M1-8. doi: 10.1016/S0304-419X(97)00004-8

311. Canman CE, Chen CY, Lee MH, Kastan MB. DNA damage responses: p53 induction, cell cycle perturbations, and apoptosis. Cold Spring Harb Symp Quant Biol. (1994) 59:277-86. doi: 10.1101/SQB.1994.059.01.032

312. Bensaad K, Vousden KH. p53: new roles in metabolism. Trends Cell Biol. (2007) 17:286-91. doi: 10.1016/j.tcb.2007.04.004

313. Braun MW, Iwakuma T. Regulation of cytotoxic T-cell responses by p53 in cancer. Transl Cancer Res. (2016) 5:692-7. doi: 10.21037/tcr.2016.11.76

314. Muñoz-Fontela C, Mandinova A, Aaronson SA, Lee SW. Emerging roles of p53 and other tumour-suppressor genes in immune regulation. Nat Rev Immunol. (2016) 16:741-50. doi: 10.1038/nri.2016.99

315. Kim T, Veronese A, Pichiorri F, Lee TJ, Jeon YJ, Volinia S, et al. p53 regulates epithelial-mesenchymal transition through microRNAs targeting ZEB1 and ZEB2. J Exp Med. (2011) 208:875-83. doi: 10.1084/jem.20110235

316. Kan G, Dong W. The expression of PD-L1 APE1 and P53 in hepatocellular carcinoma and its relationship to clinical pathology. Eur Rev Med Pharmacol Sci. (2015) 19:3063-71.

317. Dong ZY, Zhong WZ, Zhang XC, Su J, Xie Z, Liu SY, et al. Potential predictive value of TP53 and KRAS mutation status for response to PD-1 
blockade immunotherapy in lung adenocarcinoma. Clin Cancer Res. (2017) 23:3012-24. doi: 10.1016/j.jtho.2016.11.504

318. Cha YJ, Kim HR, Lee CY, Cho BC, Shim HS. Clinicopathological and prognostic significance of programmed cell death ligand-1 expression in lung adenocarcinoma and its relationship with p53 status. Lung Cancer. (2016) 97:73-80. doi: 10.1016/j.lungcan.2016.05.001

319. Wieser V, Gaugg I, Fleischer M, Shivalingaiah G, Wenzel S, Sprung $\mathrm{S}$, et al. BRCA1/2 and TP53 mutation status associates with PD-1 and PD-L1 expression in ovarian cancer. Oncotarget. (2018) 9:17501-11. doi: 10.18632/oncotarget.24770

320. Yoon KW, Byun S, Kwon E, Hwang SY, Chu K, Hiraki M, et al. Control of signaling-mediated clearance of apoptotic cells by the tumor suppressor $\mathrm{p} 53$. Science. (2015) 349:1261669. doi: 10.1126/science.1261669

321. Yu XY, Zhang XW, Wang F, Lin YB, Wang WD, Chen YQ, et al. Correlation and prognostic significance of PD-L1 and P53 expression in resected primary pulmonary lymphoepithelioma-like carcinoma. J Thorac Dis. (2018) 10:1891-902. doi: 10.21037/jtd.2018.03.14

322. Li J, Yen C, Liaw D, Podsypanina K, Bose S, Wang SI, et al. PTEN, a putative protein tyrosine phosphatase gene mutated in human brain, breast, and prostate cancer. Science. (1997) 275:1943-7. doi: $10.1126 /$ science.275.5308.1943

323. Myers MP, Pass I, Batty IH, Van der Kaay J, Stolarov JP, Hemmings $\mathrm{BA}$, et al. The lipid phosphatase activity of PTEN is critical forits tumor supressor function. Proc Natl Acad Sci USA. (1998) 95:13513-8. doi: 10.1073/pnas.95.23.13513

324. Mittendorf EA, Philip AV, Meric-Bernstam F, Qiao N, Wu Y, Harrington S, et al. PD-L1 expression in triple-negative breast cancer. Cancer Immunol Res. (2014) 2:361-70. doi: 10.1158/2326-6066.CIR-13-0127

325. Wang X, Cao X, Sun R, Tang C, Tzankov A, Zhang J, et al. Clinical significance of PTEN deletion, mutation, and loss of PTEN expression in de novo diffuse large b-cell lymphoma. Neoplasia. (2018) 20:574-93. doi: 10.1016/j.neo.2018.03.002

326. Buchakjian MR, Merritt NM, Moose DL, Dupuy AJ, Tanas MR, Henry MD. A Trp53fl/fl Ptenfl/fl mouse model of undifferentiated pleomorphic sarcoma mediated by adeno-Cre injection and in vivo bioluminescence imaging. PLoS ONE. (2017) 12:e0183469. doi: 10.1371/journal.pone.0183469

327. Xu C, Fillmore CM, Koyama S, Wu H, Zhao Y, Chen Z, et al. Loss of Lkb1 and Pten leads to lung squamous cell carcinoma with elevated PD-L1 expression. Cancer Cell. (2014) 25:590-604. doi: 10.1016/j.ccr.2014.03.033

328. Best SA, De Souza DP, Kersbergen A, Policheni AN, Dayalan S, Tull D, et al. Synergy between the KEAP1/NRF2 and PI3K pathways drives non-small-cell lung cancer with an altered immune microenvironment. Cell Metab. (2018) 27:935-43. doi: 10.1016/j.cmet.2018.02.006

329. Ivanova AV, Ivanov SV, Prudkin L, Nonaka D, Liu Z, Tsao A, et al. Mechanisms of FUS1/TUSC2 deficiency in mesothelioma and its tumorigenic transcriptional effects. Mol Cancer. (2009) 8:91. doi: 10.1186/1476-4598-8-91

330. Cao X, Zhao Y, Wang J, Dai B, Gentile E, Lin J, et al. TUSC2 downregulates PD-L1 expression in non-small cell lung cancer (NSCLC). Oncotarget. (2017) 8:107621-9. doi: 10.18632/oncotarget.22581

331. Dai B, Yan S, Lara-Guerra H, Kawashima H, Sakai R, Jayachandran G, et al. Exogenous restoration of TUSC2 expression induces responsiveness to erlotinib in wildtype Epidermal Growth Factor Receptor (EGFR) lung cancer cells through context specific pathways resulting in enhanced therapeutic efficacy. PLoS ONE. (2015) 10:e0123967. doi: 10.1371/journal.pone.0123967

332. Tan WJT, Song L, Graham M, Schettino A, Navaratnam D, Yarbrough WG, et al. Novel role of the mitochondrial protein fus1 in protection from premature hearing loss via regulation of oxidative stress and nutrient and energy sensing pathways in the inner ear. Antioxid Redox Signal. (2017) 27:489-509. doi: 10.1089/ars.2016.6851

333. Manning AL, Dyson NJ. RB: mitotic implications of a tumour suppressor. Nat Rev Cancer. (2012) 12:220-6. doi: 10.1038/nrc3216

334. Schaal C, Pillai S, Chellappan SP. The Rb-E2F transcriptional regulatory pathway in tumor angiogenesis and metastasis. Adv Cancer Res. (2014) 121:147-82. doi: 10.1016/B978-0-12-800249-0.00004-4

335. Sherr CJ, Roberts JM. Living with or without cyclins and cyclin-dependent kinases. Genes Dev. (2004) 18:2699-711. doi: 10.1101/gad.1256504
336. Jin X, Ding D, Yan Y, Li H, Wang B, Ma L, et al. Phosphorylated RB promotes cancer immunity by inhibiting NF-KB activation and PD-L1 expression. Mol Cell. (2018) 73:22-35.e6. doi: 10.1016/j.molcel.2018.10.034

337. Jeong JH, Jo A, Park P, Lee H, Lee HO. Brca2 deficiency leads to T cell loss and immune dysfunction. Mol Cells. (2015) 38:251-8. doi: 10.14348/molcells.2015.2302

338. Strickland KC, Howitt BE, Shukla SA, Rodig S, Ritterhouse LL, Liu JF, et al. Association and prognostic significance of BRCA1/2-mutation status with neoantigen load, number of tumor-infiltrating lymphocytes and expression of PD-1/PD-L1 in high grade serous ovarian cancer. Oncotarget. (2016) 7:13587-98. doi: 10.18632/oncotarget.7277

339. Dai Y, Sun C, Feng Y, Jia Q, Zhu B. Potent immunogenicity in BRCA1mutated patients with high-grade serous ovarian carcinoma. J Cell Mol Med. (2018) 22:3979-86. doi: $10.1111 / \mathrm{jcmm} .13678$

340. Horita H, Law A, Hong S, Middleton K. Identifying regulatory posttranslational modifications of PD-L1: a focus on monoubiquitinaton. Neoplasia. (2017) 19:346-53. doi: 10.1016/j.neo.2017.02.006

341. Cha JH, Yang WH, Xia W, Wei Y, Chan LC, Lim SO, et al. Metformin promotes antitumor immunity via endoplasmic-reticulumassociated degradation of PD-L1. Mol Cell. (2018) 71:606-620.e7. doi: 10.1016/j.molcel.2018.07.030

342. Ding Q, He X, Hsu JM, Xia W, Chen CT, Li LY, et al. Degradation of Mcl-1 by $\beta$-TrCP mediates glycogen synthase kinase3-induced tumor suppression and chemosensitization. Mol Cell Biol. (2007) 27:4006-17. doi: 10.1128/MCB.00620-06

343. Hart M, Concordet JP, Lassot I, Albert I, del los Santos R, Durand $\mathrm{H}$, et al. The $\mathrm{F}$-box protein $\beta$-TrCP associates with phosphorylated $\beta$ catenin and regulates its activity in the cell. Curr Biol. (1999) 9:207-10. doi: 10.1016/S0960-9822(99)80091-8

344. Wang S, Xu L, Che X, Li C, Xu L, Hou K, et al. E3 ubiquitin ligases Cbl-b and c-Cbl downregulate PD-L1 in EGFR wild-type non-small cell lung cancer. FEBS Lett. (2018) 592:621-30. doi: 10.1002/1873-3468.12985

345. Zhang J, Bu X, Wang H, Zhu Y, Geng Y, Nihira NT, et al. Cyclin D-CDK4 kinase destabilizes PD-L1 via cullin 3-SPOP to control cancer immune surveillance. Nature. (2018) 553:91-5. doi: 10.1038/nature25015

346. CDK4/6 inhibitors increase PD-L1 expression. Cancer Discov. (2018) 8:12. doi: 10.1158/2159-8290.CD-RW2017-225

347. Li J, Yu T, Yan M, Zhang X, Liao L, Zhu M, et al. DCUN1D1 facilitates tumor metastasis by activating FAK signaling and up-regulates PD-L1 in non-small-cell lung cancer. Exp Cell Res. (2018) 374:304-14. doi: 10.1016/j.yexcr.2018.12.001

348. Burr ML, Sparbier CE, Chan YC, Williamson JC, Woods K, Beavis PA, et al. CMTM6 maintains the expression of PD-L1 and regulates anti-tumour immunity. Nature. (2017) 549:101-5. doi: 10.1038/nature23643

349. Mezzadra R, Sun C, Jae LT, Gomez-Eerland R, de Vries E, Wu W, et al. Identification of CMTM6 and CMTM4 as PD-L1 protein regulators. Nature. (2017) 549:106-10. doi: 10.1038/nature23669

350. Visan I. CMTM6 controls PD-L1. Nat Immunol. (2017) 18:1067. doi: 10.1038/ni.3844

351. Wang H, Yao H, Li C, Shi H, Lan J, Li Z, et al. HIP1R targets PD-L1 to lysosomal degradation to alter T cell-mediated cytotoxicity. Nat Chem Biol. (2018) 15:42-50. doi: 10.1038/s41589-018-0161-x

352. Breitling J, Aebi M. N-linked protein glycosylation in the endoplasmic reticulum. Cold Spring Harb Perspect Biol. (2013) 5:a013359. doi: 10.1101/cshperspect.a013359

353. Schwarz F, Aebi M. Mechanisms and principles of N-linked protein glycosylation. Curr Opin Struct Biol. (2011) 21:576-82. doi: 10.1016/j.sbi.2011.08.005

354. Li CW, Lim SO, Chung EM, Kim YS, Park AH, Yao J, et al. Eradication of triple-negative breast cancer cells by targeting glycosylated PD-L1. Cancer Cell. (2018) 33:187-201.e10. doi: 10.1016/j.ccell.2018. 01.009

355. Cheng X, Veverka V, Radhakrishnan A, Waters LC, Muskett FW, Morgan $\mathrm{SH}$, et al. Structure and interactions of the human programmed cell death 1 receptor. J Biol Chem. (2013) 288:11771-85. doi: 10.1074/jbc.M112.448126

356. Maher CM, Thomas JD, Haas DA, Longen CG, Oyer HM, Tong JY, et al. Small-molecule sigmal modulator induces autophagic degradation of 
PD-L1. Mol Cancer Res. (2018) 16:243-55. doi: 10.1158/1541-7786.MCR17-0166

357. Salatino M, Girotti MR, Rabinovich GA. Glycans pave the way for immunotherapy in triple-negative breast cancer. Cancer Cell. (2018) 33:1557. doi: 10.1016/j.ccell.2018.01.015

358. Chen S, Zhu B, Yin C, Liu W, Han C, Chen B, et al. Palmitoylation-dependent activation of MC1R prevents melanomagenesis. Nature. (2017) 549:399-403. doi: $10.1038 /$ nature 23887

359. Linder ME, Deschenes RJ. Palmitoylation: policing protein stability and traffic. Nat Rev Mol Cell Biol. (2007) 8:74-84. doi: 10.1038/nrm2084

360. Li W, Li W, Zou L, Ji S, Li C, Liu K, et al. Membrane targeting of inhibitory Smads through palmitoylation controls TGF- $\beta$ /BMP signaling. Proc Natl Acad Sci USA. (2017) 114:13206-11. doi: 10.1073/pnas.1710540114

361. Blanc M, David F, Abrami L, Migliozzi D, Armand F, Bürgi J, et al. SwissPalm: protein palmitoylation database. F1000Res. (2015) 4:261. doi: 10.12688/f1000research.6464.1

362. Yang Y, Hsu JM, Sun L, Chan LC, Li CW, Hsu JL, et al. Palmitoylation stabilizes PD-L1 to promote breast tumor growth. Cell Res. (2018) 29:83-6. doi: 10.1038/s41422-018-0124-5

363. Schmidt MF, Schlesinger MJ. Fatty acid binding to vesicular stomatitis virus glycoprotein: a new type of post-translational modification of the viral glycoprotein. Cell. (1979) 17:813-9. doi: 10.1016/0092-8674(79)90321-0

364. Mitchell DA, Vasudevan A, Linder ME, Deschenes RJ. Protein palmitoylation by a family of DHHC protein S-acyltransferases. J Lipid Res. (2006) 47:111827. doi: 10.1194/jlr.R600007-JLR200

365. Yao H, Lan J, Li C, Shi H, Brosseau JP, Wang H, et al. Inhibiting PD-L1 palmitoylation enhances T-cell immune responses against tumours. Nat Biomed Eng. (2019) 3:306-17. doi: 10.1038/s41551-0190375-6

366. Liu J, Hamrouni A, Wolowiec D, Coiteux V, Kuliczkowski K, Hetuin D, et al. Plasma cells from multiple myeloma patients express B7-H1 (PD-L1) and increase expression after stimulation with IFN- $\gamma$ and TLR ligands via a MyD88-, TRAF6-, and MEK-dependent pathway. Blood. (2007) 110:296304. doi: 10.1182/blood-2006-10-051482

367. Fei Z, Deng Z, Zhou L, Li K, Xia X, Xie R. PD-L1 induces epithelial mesenchymal transition in nasopharyngeal carcinoma cells through activation PI3K/AKT pathway. Oncol Res. (2019). doi: 10.3727/096504018X15446984186056. [Epub ahead of print].

368. Tu X, Qin B, Zhang Y, Zhang C, Kahila M, Nowsheen S, et al. PD-L1 (B7-H1) competes with the RNA exosome to regulate the DNA damage response and can be targeted to sensitize to radiation or chemotherapy. Mol Cell. (2019) 74:1-12. doi: 10.1016/j.molcel.2019.04.005

Conflict of Interest Statement: The authors declare that the research was conducted in the absence of any commercial or financial relationships that could be construed as a potential conflict of interest.

Copyright (C) 2019 Shen, Zhang, Li, Li, Wang and Xu. This is an open-access article distributed under the terms of the Creative Commons Attribution License (CC BY). The use, distribution or reproduction in other forums is permitted, provided the original author(s) and the copyright owner(s) are credited and that the original publication in this journal is cited, in accordance with accepted academic practice. No use, distribution or reproduction is permitted which does not comply with these terms. 